\title{
Mutations in the HvDWARF, HvCPD and HvBRI1 Genes-Involved in Brassinosteroid Biosynthesis/Signalling: Altered Photosynthetic Efficiency, Hormonal Homeostasis and Tolerance to High/Low Temperatures in Barley
}

\author{
Iwona Sadura ${ }^{1}$ - Ewa Pociecha ${ }^{2} \cdot$ Michał Dziurka $^{1} \cdot$ Jana Oklestkova ${ }^{3} \cdot$ Ondrej Novak ${ }^{3} \cdot$ Damian Gruszka $^{4}$. \\ Anna Janeczko ${ }^{1}$
}

Received: 6 July 2018 / Accepted: 14 December 2018 / Published online: 11 February 2019

(c) The Author(s) 2019

\begin{abstract}
Brassinosteroids (BR) are steroid phytohormones that are involved in the growth and stress response in plants, but the precise mechanisms of their action are still being discovered. In our study we have used BR-deficient barley mutants 522DK and BW084 (which carry missense mutations in the $H v D W A R F$ and $H v C P D$ genes, respectively). We have also used a BR-signalling mutant that harbors missense substitutions in the HvBRIl gene. Our aim was (1) to find out if the content of phytohormones in the mutants grown at $20^{\circ} \mathrm{C}$ is different than in the wild types and whether/how the content of phytohormones changes after plant acclimation at temperatures of $5^{\circ} \mathrm{C}$ and $27{ }^{\circ} \mathrm{C}$, , (2) to characterise the effectiveness of the light reactions of photosynthesis of the barley mutants in comparison to wild types at various temperatures, and (3) to verify the impact of mutations on the tolerance of barley to high and low temperatures. Hormonal characteristics of the BR mutants of barley show the complexity of the interactions between BR and other plant hormones that are additionally modified by temperature and possibly by other factors. The results suggest the participation of BR in auxin catabolism. Further, BR appears to play a role in maintaining the ABA-ABAGlc balance. As for the gibberellin content in plants at a temperature of $20{ }^{\circ} \mathrm{C}$, more in-depth studies will be required to explain the contradictory effects regarding the accumulation of GA3, GA4 and GA5, which appears to be dependent on the type of mutation and connected to the BR level. A fast-kinetic chlorophyll $a$ fluorescence analysis has revealed that the mutants had lower values of energy absorption than the wild types, but the values of the energy transferred via the electron-transport chain was maintained at the wild-type level. We presumed that BR are involved in regulating plant acclimation to extreme (low/high) temperatures, thus the BR-deficient and BR-signalling mutants should be less tolerant to low/high temperatures when compared to the wild types. Unexpectedly, all of the mutants showed a higher tolerance to high temperatures than the wild types. The BW084 and BW312 mutants were less tolerant to frost than the wild type, but 522DK had a similar frost tolerance as the reference wild-type cultivar.
\end{abstract}

Keywords Barley $\cdot$ Brassinosteroid content $\cdot$ Frost $\cdot$ Heat $\cdot$ Phytohormones $\cdot$ PSII efficiency

Electronic supplementary material The online version of this article (https://doi.org/10.1007/s00344-019-09914-z) contains supplementary material, which is available to authorized users.

Anna Janeczko

ania@belanna.strefa.pl

1 Polish Academy of Sciences, The Franciszek Górski Institute of Plant Physiology, 30-239 Krakow, Poland

2 University of Agriculture in Krakow, Department of Plant Physiology, Podłużna 3, 30-239 Krakow, Poland
3 Laboratory of Growth Regulators, Centre of the Region Haná for Biotechnological and Agricultural Research, Institute of Experimental Botany ASCR, Palacký University, Šlechtitelů 27, 78371 Olomouc, Czech Republic

4 University of Silesia, Faculty of Biology and Environment Protection, Department of Genetics, Jagiellonska 28, 40-032 Katowice, Poland 


\section{Introduction}

Temperature stress is, among the abiotic stresses, a particularly serious problem in agriculture and horticulture. Some species are very sensitive to cold, while frost, especially when there is insufficient snow cover on fields, can cause significant yield losses of winter crops. High-temperature stress, in turn, is particularly dangerous to plants when it is combined with drought during the growing season. In the case of barley cultivars, the influence of high temperature on PSII efficiency (Janeczko et al. 2011; Oukarroum et al. 2016) and genes encoding antioxidant enzymes and heat shock proteins (Faralli et al. 2015) was studied. At low temperature conditions the metabolic changes associated with cold adaptation and modifications of expression of the cold-regulated (COR) genes in barley cultivars were also investigated (Stanca et al. 1996). Moreover, characterisation of the CBF (C-repeat binding factor) gene family (which induces the COR expression) was performed in barley cultivars (Skinner et al. 2005). Because all crops are often exposed to extreme temperatures combined with a lack or excess of water, too little or too intense light, nutritional deficits, etc. during their life cycle (Koyro et al. 2012), discovering/studying the mechanisms of the actions of regulators (including plant hormones, for example, brassinosteroids) that stimulate the processes that counteract the effects of stress is very important from the practical point of view. The results of these studies may contribute to obtaining and incorporating new, more resistant cultivars of crops or to prepare agrochemicals that have protective/anti-stress properties for farming applications, especially because abiotic stress is considered to be a major cause of crop losses (Hasanuzzaman et al. 2012; Koyro et al. 2012).

Brassinosteroids (BR) belong to steroid phytohormones that were discovered in the 1970s (Mitchell et al. 1970; Grove et al. 1979). BR are known as regulators of plant growth and development. BR have also been found to be capable of minimising the damage that is caused by various kinds of stresses, including extreme temperatures. In plants that are subjected to high/low temperatures, BR counteract growth inhibition, reduce biomass losses and increase plant survival rates (Sadura and Janeczko 2018). At the cellular/molecular levels, BR have a multidirectional activity that regulates the cellular metabolism of plants that are exposed to temperature stress (Sadura and Janeczko 2018). On the other hand, the growth, development and stress responses in plants are regulated by the coordinated interplay of phytohormones such as auxins, gibberellins (GA), cytokinins, abscisic acid (ABA) or ethylene (Bari and Jones 2009; Small and Degenhardt 2018). Simultaneously, plant hormones control their own biosynthesis and transport. GA interact with $\mathrm{ABA}$ in an antagonistic manner-GA stimulate germination, growth and flowering, whereas $\mathrm{ABA}$ inhibits these processes (Weiss and Ori 2007; Shu et al. 2018). Auxins promote the influence of GA on the regulation of cell expansion and tissue differentiation by repressing the major negative regulators of the GA signalling-the DELLA proteinsand by regulating the biosynthesis of GA (Weiss and Ori 2007). The ratio of auxin/cytokinin plays an important role in forming shoots and roots (El-Yazal et al. 2015). Cytokinins positively regulate auxin biosynthesis. Although ABA, jasmonates (JA) and salicylic acid (SA) promote stomatal closure, cytokinins and auxins induce stomatal opening during stress (Peleg and Blumwald 2011). Finally, the most important plant physiological process-photosynthesis-is controlled by an integrated system of hormonal interplay (Gururani et al. 2015). In the case of barley cultivars, it is known that phytohormones regulate agronomically important traits (Marzec and Alqudah 2018). However, there are still many unknowns, including barley hormonal regulation under temperature stress. In the case of barley mutants with disturbances in the BR biosynthesis and signalling, according to our best knowledge, hormonal homeostasis has been investigated only in the case of drought stress (Janeczko et al. 2016; Gruszka et al. 2016a). Although BR also contribute to the functioning of the hormonal network, knowledge about this phenomenon is rather limited, and little is known about the influence of various temperatures on the interplay between BR and other phytohormones (Sadura and Janeczko 2018). The impact of BR on the temperature-dependent accumulation of other hormones has been studied in experiments with an exogenous application of BR (Bajguz 2009; Liu et al. 2011; Pociecha et al. 2017). Liu et al. (2011) studied C. bungeana cell cultures subjected to $0{ }^{\circ} \mathrm{C}$ and $4{ }^{\circ} \mathrm{C}$ and observed that on a medium with BR (24-epibrassinolide), cells accumulated more ABA compared to the untreated control. On the other hand, according to Bajguz (2009), algae cells cultured at high temperature on a medium supplemented with BR (brassinolide) contained more ABA compared to cells without BR supplementation. Application of 24-epibrassinolide $\left(0.25 \mathrm{mg} \mathrm{dm}^{-3}\right)$ to perennial ryegrass combined with cold $\left(4^{\circ} \mathrm{C}, 6\right.$ weeks) resulted in an increased content of the ethylene precursor (ACC) compared to the plants without the BR treatment (Pociecha et al. 2017). In view of these data, it would be worth verifying/expanding this knowledge in studies on BR mutants.

Barley (Hordeum vulgare L.) - the species used in our experiment, is an important crop plant and the fourth most abundant cereal in both area and tonnage harvested, grown all over the world. Several genes involved in BR metabolism have been identified in barley, and collections of barley mutants with disturbances in BR biosynthesis and signalling 
are available (Gruszka et al. 2011a, b, 2016b; Dockter et al. 2014). Among them there are genes that encode the enzymes HvDWARF (represented by the 522DK mutant) and HvCPD (represented by the BW084 mutant) that mediate BR biosynthesis, as well as a gene encoding the BR receptorHvBRI1 (represented by the BW312 mutant). Various mutations of these genes often result in semi-dwarfism and these semi-dwarf barley mutants, that have disturbances in the BR biosynthesis and signalling, are useful in studies of the mechanisms of BR action in plants and plant interaction with the environment. It is known that semi-dwarf accessions of cereal crops are more tolerant to lodging under unfavourable weather conditions, and, therefore, they have significantly contributed to the success of the so-called 'Green Revolution' in the second half of the twentieth century (Hedden 2003; Chono et al. 2003). However, fine-tuning of the BRrelated growth reduction is still required for the efficient breeding of cereal crops, especially when the possibility of global climate change is taken into account. Our recent studies have indicated that in response to drought stress the semi-dwarf barley mutants (BW084 and BW312) exhibited delayed wilting when compared to the wild-type cultivar (Gruszka et al. 2016a). Thus, they may be considered as a potential alternative in future barley breeding programs.

In the present study, we have gained insight into the hormonal homeostasis in the BR-biosynthesis and signalling mutants of barley by answering the following question: is the content of phytohormones in the mutants grown at $20^{\circ} \mathrm{C}$ different than in the wild types and whether/how the content of phytohormones changes after plant acclimation at temperatures of $5{ }^{\circ} \mathrm{C}$ and $27{ }^{\circ} \mathrm{C}$ ? Changes in hormonal homeostasis may be accompanied by alterations in the intensity of various physiological processes and may determine the response of plants to stress conditions. That is why we have also characterised the effectiveness of the light reactions of photosynthesis of barley mutants in comparison to wild types at various temperatures. The impact of mutations in the BR biosynthesis and signalling genes on the tolerance of plants to high temperature and frost was also investigated.

\section{Materials and Methods}

\section{Plant Material}

In our experiments, spring barley (Hordeum vulgare L.) cultivars (Delisa and Bowman) and their mutants were selected according to reports by Gruszka et al. (2011b) and Dockter et al. (2014), and the seeds were obtained from the collection of the Department of Genetics, University of Silesia (Poland).

The 522DK mutant is derived from the Delisa cultivar. In this mutant, the $\mathrm{G}>\mathrm{A}$ substitution was identified at position
1130 of the HvDWARF transcript (Gruszka et al. 2011a) and at position 3031 in the gene sequence (Gruszka et al. 2016b), which changes the valine-341 residue into isoleucine. The substituted valine-341 is a highly conserved residue that is present in an analogous position in the homologous DWARF polypeptides in barley, rice, Arabidopsis and tomato. Because the HvDWARF gene encodes the brassinosteroid C6-oxidase, which is involved in the BR biosynthesis (catalyses production of castasterone), the mutant shows a reduced content of castasterone (Gruszka et al. 2016b).

The material of this study also contained the previously characterised barley Near-Isogenic Lines (NILs), which represent mutants that have defects in BR biosynthesis and signalling, along with the reference cultivar Bowman (Dockter et al. 2014). The BW084 (brh13.p) NIL represents a mutant defective in BR biosynthesis, which produces a decreased content of castasterone. The BW084 NIL carries a missense mutation (C2562T substitution) in the $H v C P D$ gene, which encodes the C-23 $\alpha$-hydroxylase cytochrome P450 90A1 (CYP90A1) that catalyses the early stages of BR biosynthesis. The $\mathrm{C} 2562 \mathrm{~T}$ transition causes a substitution of the highly conserved amino acid residue (Pro-445 to Leu). Pro-445 is located within a highly conserved heme binding site in the C-terminal part of the HvCPD enzyme (Dockter et al. 2014).

The BW312 (ert-ii.79) NIL is defective in BR perception. The BR perception abnormality is caused by substitutions in the BR receptor kinase-BRI1. Consequently, higher content of castasterone is accumulated in BW312 when compared to the Bowman cultivar. The mutant allele contains a double substitution CC1760/1761AA. The substituted amino acid residue (Thr-573 to Lys) is located in the steroid-binding domain of the BR receptor. The introduction of the charged Lys-573 into the hydrophobic active site surrounding the residues, which destroys charge neutrality, is expected to prevent the binding of the BR molecules (Dockter et al. 2014).

Additionally, cultivars of spring and winter barley (Kucyk and Fridericus, respectively) were used in the preliminary experiments during tests to determine the low and high temperatures to be used for main studies on the mutants.

\section{Experimental Design}

\section{Plant Culture}

The seeds were germinated for 3 days on plastic vessels $(10 \mathrm{~cm} \times 10 \mathrm{~cm} \times 3 \mathrm{~cm})$ with moist filter paper in the dark at $24{ }^{\circ} \mathrm{C}$. There were 40 seeds and $10 \mathrm{~mL}$ of water per vessel. After germination, the seedlings were transplanted into pots containing soil. There were 15-20 plants per pot. Each pot $(40 \mathrm{~cm} \times 15 \mathrm{~cm} \times 15 \mathrm{~cm})$ contained $3 \mathrm{~kg}$ of mixed and sieved soils: 'Eco-ziem universal soil' (Jurków, Poland), soil from the cultivation plots at the University of Agriculture 
(Krakow) and sand. The plants were then grown in a growth chamber at $20{ }^{\circ} \mathrm{C}(\mathrm{d} / \mathrm{n})$ under a 16 -h photoperiod for 19 days until they reached the stage with 3-4 leaves. The potted plants were then divided into two groups. The first group was acclimated to $5{ }^{\circ} \mathrm{C}(\mathrm{d} / \mathrm{n})$ under a 8-h photoperiod for 3 weeks, whereas the second group was acclimated to $27^{\circ} \mathrm{C}$ (d/n) under a 16-h photoperiod for 7 days. After the plants had been acclimated, they had four well-developed leaves and sometimes a young fifth leaf. Light intensity in the growth chambers was $170 \mu \mathrm{mol} \mathrm{m}{ }^{-2} \mathrm{~s}^{-1}$ provided by HPS Philips SON-T AGRO $400 \mathrm{~W}$ lamps.

Non-invasive measurements of the fast fluorescence kinetic chlorophyll $a$ test were performed on plants before their acclimation (at $20^{\circ} \mathrm{C}$ ), and then for both groups of acclimated plants (on the last day of acclimation). Similarly, the leaf samples for the analysis of phytohormones were collected from the plants before acclimation, and then on the last day of the acclimation at $27^{\circ} \mathrm{C}$ and $5{ }^{\circ} \mathrm{C}$. The exception was the analysis of BR content, where samples were collected: before acclimation, on day 3 of acclimation at $27^{\circ} \mathrm{C}$, on day 7 (last) of acclimation at $27^{\circ} \mathrm{C}$, on day 10 of acclimation at $5{ }^{\circ} \mathrm{C}$, and on day 21 of acclimation at $5{ }^{\circ} \mathrm{C}$.

After the measurements and leaf sampling, the plants acclimated to $5{ }^{\circ} \mathrm{C}$ were exposed to frost, whereas the plants acclimated to $27{ }^{\circ} \mathrm{C}$ were exposed to heat. The survival rate of the plants was estimated after these exposures.

\section{Frost Test and Estimation of the Plant Survival Rate}

After acclimation at $5{ }^{\circ} \mathrm{C}$, the pots with plants of cv. Delisa, $\mathrm{cv}$. Bowman and their mutants were divided into two groups that were exposed to frost in the dark growth chamber separately: $-6{ }^{\circ} \mathrm{C}$ (first group), $-8{ }^{\circ} \mathrm{C}$ (second group). The starting point was $5{ }^{\circ} \mathrm{C}$, after which the temperature was lowered by $3 \% \mathrm{~h}$ until the required frost level was reached. The plants were exposed to the frost treatment (exactly -6 or $-8{ }^{\circ} \mathrm{C}$ ) for $6 \mathrm{~h}$, and then the temperature was increased by $3 \% \mathrm{~h}$ until $5{ }^{\circ} \mathrm{C}$ was reached. Finally, the temperature was set at $12{ }^{\circ} \mathrm{C}(\mathrm{d} / \mathrm{n})$ and the plants were left for 2 weeks to recover (12-h photoperiod). After this period, the plant survival rate was estimated based on the Larsen (1978) visual scale ( $0-9$ scale of regrowth after frost treatment), where 0 indicates completely dead plants with no signs of leaf elongation, whereas 9 means no symptoms of injury. For a detailed description of the scale see Pociecha et al. (2016).

The temperatures for testing were selected based on a preliminary experiment where cultures of two barley cultivars (Kucyk — spring barley and Fridericus - winter barley) were prepared. Plants were grown and acclimated at $5{ }^{\circ} \mathrm{C}$ identically to the experimental design described above, and then exposed to frost: $-4{ }^{\circ} \mathrm{C},-6{ }^{\circ} \mathrm{C},-8{ }^{\circ} \mathrm{C},-10{ }^{\circ} \mathrm{C}$ and $-12{ }^{\circ} \mathrm{C}$. Based on results of the aforementioned regrowth test, the temperatures of $-6{ }^{\circ} \mathrm{C}$ and $-8{ }^{\circ} \mathrm{C}$ were selected.
After exposure to $-6{ }^{\circ} \mathrm{C}$, the regrowth of all of the plants reached a value of 9 points on the Larsen scale, but after exposure to $-8{ }^{\circ} \mathrm{C}$, the plants of the spring cv. Kucyk had a regrowth that was estimated at only four points on the 9-point scale. All of the results of this preliminary test are presented in Supplementary Material: Figure S1A.

\section{Heat Test and Estimation of the Plant Survival Rate}

After acclimation at $27{ }^{\circ} \mathrm{C}$, the potted plants of cv. Delisa, $\mathrm{cv}$. Bowman and their mutants were divided into two groups and exposed to temperatures of $38^{\circ} \mathrm{C}$ (first group) and $45^{\circ} \mathrm{C}$ (second group) for two hours under light conditions in the growth chamber. To examine any heat-induced injury after the heat treatment, the following parameters were analysed: (1) performance index (P.I. ${ }_{\mathrm{ABS}}$ ) - photosynthetic parameter that gives information about functioning of the photosystem II; (2) membrane permeability-measured as the amount of electrolyte leakage; (3) leaf blade damage-percentage of the injured (darkened, dried) leaf area in relation to the total leaf area. All leaves of the tested plants were analysed.

The temperatures for the treatment were selected based on the preliminary experiment performed on the barley cultivars Kucyk (spring barley) and Fridericus (winter barley). Plants were grown and acclimated at $27{ }^{\circ} \mathrm{C}$ identically to the experimental design described above and were then exposed to heat: $38^{\circ} \mathrm{C}, 40{ }^{\circ} \mathrm{C}, 42{ }^{\circ} \mathrm{C}, 43{ }^{\circ} \mathrm{C}, 45^{\circ} \mathrm{C}, 48{ }^{\circ} \mathrm{C}$ and $50{ }^{\circ} \mathrm{C}$ for $2 \mathrm{~h}$. Based on results, which are presented in Supplementary Material: Figure S1B, C, D, the temperatures of $38{ }^{\circ} \mathrm{C}$ and $45^{\circ} \mathrm{C}$ were selected for experiments on the mutants and their wild types. These temperatures caused a decrease in the values of the vitality of photosystem II (P.I. ABS $_{\text {) }}$ ) in both cultivars and resulted in visible, but not lethal, damage to the leaf blade in the spring cv. Kucyk.

\section{Measurements}

\section{Fast Kinetics Chlorophyll a Fluorescence}

A measurement of chlorophyll $a$ fluorescence was performed to estimate the efficiency of photosystem II (PSII) using a Plant Efficiency Analyser (PEA, Hansatech Ltd., King's Lynn, England). Before the measurement, the leaves were adapted to the dark for $30 \mathrm{~min}$. Details of the procedure are given in the paper by Skoczowski et al. (2011). The following phenomenological parameters of the energy flow were calculated using the technical fluorescence parameters that were obtained from the fluorescence curve: the energy absorption by antenna pigments $\left(\mathrm{ABS} / \mathrm{CS}=F_{\mathrm{m}}\right.$ ), the amount of energy trapped in the reaction centre $\left(\mathrm{TRo} / \mathrm{CS}=F_{\mathrm{v}} / F_{\mathrm{m}}\right.$ $(\mathrm{ABS} / \mathrm{CS})$ ), the energy flux for electron transport (ETo/ $\left.\mathrm{CS}=\left(F_{\mathrm{v}} / F_{\mathrm{m}}\right)\left(1-V_{\mathrm{J}}\right) F_{\mathrm{m}}\right)$, and the dissipation of energy as heat $(\mathrm{DIo} / \mathrm{CS}=(\mathrm{ABS} / \mathrm{CS})-(\mathrm{TRo} / \mathrm{CS}))$, where $\mathrm{CS}$ is the 
sample cross section (Strasser et al. 2000). Moreover, the results of the so-called performance index (P.I. . $_{\mathrm{ABS}}$ ), which is a general indicator of plant vitality, were calculated according to Strasser et al. (2000). The PSII efficiency measurements were performed in 15 replicates for each line/cultivar and treatment. One replicate was one leaf of an individual plant. In the main experiments, in the case of cv. Delisa, cv. Bowman and their mutants, a second leaf (from the base) was measured. In the preliminary experiments, in the fastgrowing cvs. Kucyk and Fridericus, these parameters were measured on a third leaf.

\section{Analysis of Brassinosteroids}

BRs were isolated and identified using the modified methods of Oklestkova et al. (2017). Briefly, samples of the leaf material ( $1 \mathrm{~g}$ fresh weight) were homogenised using liquid $\mathrm{N}_{2}$ and $20 \mathrm{~mL}$ ice-cold $80 \%$ methanol. Samples were then centrifuged. Internal standards with deuterium-labelled BR ( $25 \mathrm{pmol} / \mathrm{sample})$ were added to the supernatant. Next, the supernatant was passed through Discovery columns (Supelco, Bellefonte, PA USA) and immunoaffinity columns (Laboratory of Growth Regulation, Olomouc, Czech Republic). The samples, which were eluted with cold $100 \%$ methanol, were dried and resuspended again in a small amount of methanol to be measured on a UHPLC with a tandem mass spectrometry (UHPLC-MS/MS) using the ACQUITY UPLC® I-Class System (Waters, Milford, MA, USA) and a Xevo ${ }^{\text {TM }}$ TQ-S MS triple quadrupole mass spectrometer (Waters MS Technologies, Manchester, UK). The analyses were performed in four repetitions.

\section{Analysis of Other Phytohormones}

Phytohormone analysis was performed as described by Dziurka et al. (2016). All the aerial parts of the plants were cut off, the material was cut into small pieces and $1 \mathrm{~g}$ samples were prepared. The extraction and purification procedure was performed as described by Dziurka et al. (2016). The analyses were performed in three independent replicates on a Agilent Infinity 1260 UHPLC apparatus (Agilent, Waldbronn, Germany), which was coupled to a triple quadruple mass spectrometer (6410 Triple Quad LC/MS, Agilent, Santa Clara, CA, USA) equipped with electrospray ionisation (ESI). Separation was performed on an Ascentis Express RP-Amide analytical column $(2.7 \mu \mathrm{m}, 2.1 \mathrm{~mm} \times 75 \mathrm{~mm}$; Supelco, Bellefonte, PA, USA). The technical details can be found in the paper by Dziurka et al. (2016). The following hormones were quantified: auxins: indole-3-acetic acid (IAA), oxindole-3-acetic acid (oxIAA), indole-3-butyric acid (IBA), indole-3-acetic acid methyl ester (IAAMe); cytokinins: trans-Zeatin (t-Z), trans-Zeatin-O-glucoside (t-ZOG), dihydrozeatin (DHZ), cisZeatin (c-Z); gibberellins: gibberellin $\mathrm{A}_{1}(\mathrm{GA} 1)$, gibberellic acid (GA3), gibberellin $\mathrm{A}_{4}(\mathrm{GA} 4)$, gibberellin $\mathrm{A}_{5}(\mathrm{GA} 5)$, gibberellin $\mathrm{A}_{6}(\mathrm{GA6})$; abscisic acid (ABA), abscisic acid glucosyl ester (ABAGlc) and salicylic acid (SA). Additionally, the total content of auxin, gibberellin and cytokinin was calculated as the sum of specific components.

Multiple reactions monitoring (MRM) transitions for the analyzed phytohormones and internal standards used are given in Supplementary Material: Table S1.

\section{Membrane Permeability}

Pieces from the middle part of a fully expanded leaf were cut into $20 \mathrm{~mm}$ sections. A piece of sample from each treatment was placed in separate vials with $10 \mathrm{~cm}^{3}$ of ultrapure water and shaken (100 rpm, Labmed International, Inc) at $20^{\circ} \mathrm{C}$. After $24 \mathrm{~h}$, the electrical conductivity $(C 1)$ was measured using a conductometer (CI 317, Elmetron, Poland). The vials with the samples were then frozen for $24 \mathrm{~h}$ at $-80{ }^{\circ} \mathrm{C}$, and, after thawing, they were shaken again for $24 \mathrm{~h}$ as described above. Then, the conductivity was measured again and the obtained values represented the total ion content $(C 2)$ in the leaf pieces. Membrane permeability was expressed as the percentage of total electrolyte leakage $(\mathrm{EL})(\mathrm{EL}=[C 1 \times 100] / C 2)$. All the measurements were performed in ten biological replicates. One replicate was one leaf of an individual plant. In the main experiments, in the case of cv. Delisa, cv. Bowman and their mutants, the samples were taken from a second leaf. In the preliminary experiments, in the cvs. Kucyk and Fridericus, a third leaf was sampled.

\section{Evaluating Leaf Injuries to Estimate Heat Tolerance}

All the leaves from a whole plant were cut off and the percentage of injured (discoloured and withered) leaf area was estimated using a WinDIAS 3 Image Analysis System (Delta-T Devices Ltd, Cambridge, UK).

\section{Statistical Analysis}

Statistical analysis (ANOVA, post hoc test) was performed using Statistica 13.1, which is distributed by StatSoft (Tulsa, USA). For the statistical analysis in the study, when more than two groups were compared, Duncan's test was used. The Student's t test, which allows two groups to be compared, was only used to estimate the statistical significances of the effects that were observed in the Delisa cultivar and the 522DK mutant. In Figs. 1, 2, 3, 4, 5, 6 the mean values are plotted with standard error bars. 
Fig. 1 Content of auxins in the barley cv. Delisa and its 522DK mutant (a, c, e, $\mathbf{g}, \mathbf{i})$ and in the barley cv. Bowman and its BW084 and BW312 mutants (b, d, f, h, j) at $20^{\circ} \mathrm{C}$ and after acclimation at $5{ }^{\circ} \mathrm{C}$ and $27^{\circ} \mathrm{C}$. The mean values are shown with bars that represent SE. Significant differences between cv. Delisa and 522DK-Student's $t$ test; between cv. Bowman and its mutants-Duncan's test, $(P \leq 0.05)$ for each temperature are indicated by different letters
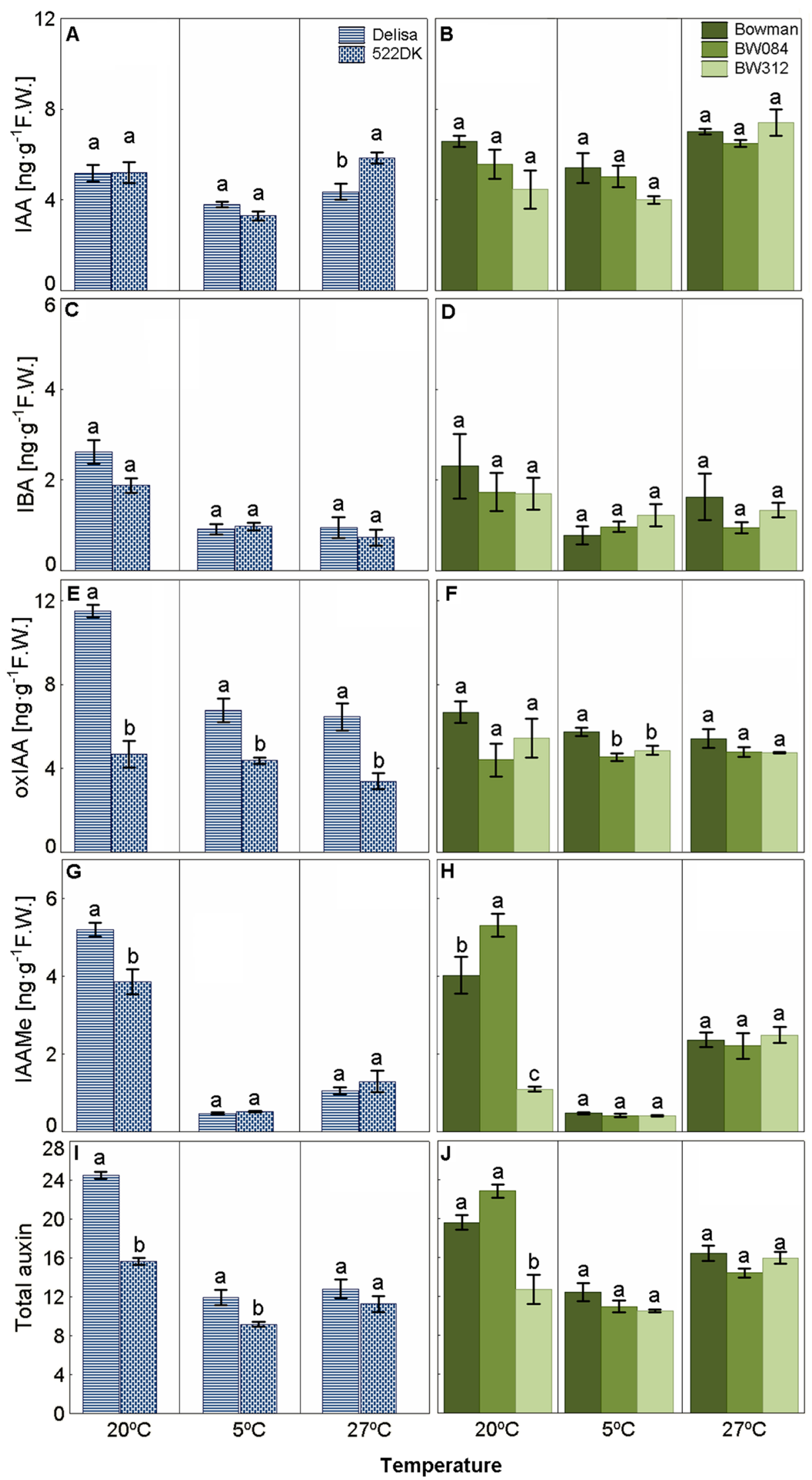


\section{Results and Discussion}

\section{Characterisation of the Hormonal Homeostasis of the Barley BR Mutants Grown at $20^{\circ} \mathrm{C}$, and then Acclimated to $5^{\circ} \mathrm{C}$ and $27^{\circ} \mathrm{C}$}

Plant hormonal homeostasis is influenced by environmental conditions and, among them, ambient temperature is one of the most important factors. Hormone accumulations, the mechanisms of their biosynthesis or hormone cross talk are the factors that are most often characterised at a temperature of about $20^{\circ} \mathrm{C}$ (Janeczko and Swaczynova 2010; Dziurka et al. 2016; Gruszka et al. 2016a, b). Our studies were aimed at characterising the hormonal homeostasis of the BR-biosynthesis and BR-signalling defective mutants incubated at low, optimal or high temperatures. Although brassinosteroids are known as important players in the hormonal network, knowledge about their interplay with other phytohormones is limited, especially in terms of the influence on plant acclimation to altered temperature. Moreover, much of the data originate from experiments that use exogenous BR application and our studies on the BR mutants have enabled some of these findings to be verified.

In our experiment, BR-deficient and BR-signalling defective barley mutants are characterised by the altered hormonal homeostasis compared to the wild types, which provide information about the complicated links between BR biosynthesis/signalling and the regulation of the accumulation of other phytohormones, additionally dependent on the temperature during plant growth.

\section{Brassinosteroids}

We were able to determine three brassinosteroids-brassinolide, castasterone and 28-homocastasterone (Tables 1,2).
In comparison to Delisa, the content of castasterone was significantly lower in the 522DK mutant regardless of growth temperature (Table 1). This is a result of disturbances in the BR biosynthetic pathway in 522DK and the data agree with our previous studies of mutants growing in different conditions and different experimental model (Gruszka et al. 2016b). Interestingly, in these earlier studies we did not find brassinolide or 28-homocastasterone in Delisa and 522DK. In the present experiment, brassinolide was detected only in plants growing at a temperature of $20^{\circ} \mathrm{C}$, and the content of this steroid was lower in 522DK than in Delisa. This is an effect of deficiency of the direct brassinolide precursor (castasterone) in the brassinolide biosynthetic pathway (Zhao and Li 2012). The content of 28-homocastasterone was a little lower in 522DK than in Delisa at $20{ }^{\circ} \mathrm{C}$ and at $27{ }^{\circ} \mathrm{C}$ after 7 days of acclimation and at $5{ }^{\circ} \mathrm{C}$ after 21 days of acclimation, but statistical significance was proven only for the mutant at $27^{\circ} \mathrm{C}$. 28 -Homocastasterone has a different biosynthetic pathway, independent from castasterone, and is biosynthesised from sitosterol, not from campesterol (Joo et al. 2015). According to these authors, 28-homocastasterone may be converted to castasterone. Perhaps this phenomenon had taken place in the $522 \mathrm{DK}$ plants, at $20^{\circ} \mathrm{C}$ and after longer periods of acclimation, to alleviate a deficit of castasterone, but this will require further studies.

In comparison to Bowman, the content of castasterone was significantly higher in the signalling mutant BW312 regardless of growth temperature (Table 2). This agrees with our previous studies on this mutant cultured in a different experimental model (Gruszka et al. 2016a). According to data published by Gruszka et al. (2016a), BW084 was characterised by a dramatically decreased (but detectable) content of castasterone. In the present studies, the content of castasterone was below the detection limit. Similarly, as in the cases of Delisa and 522DK, brassinolide was only detected in Bowman and BW312 growing at $20{ }^{\circ} \mathrm{C}$. In
Table 1 Content of brassinosteroids in the barley cv. Delisa and its mutant 522DK growing at $20^{\circ} \mathrm{C}$ and after acclimation at $5{ }^{\circ} \mathrm{C}(10$ and 21 days) and $27^{\circ} \mathrm{C}(3$ and 7 days)

\begin{tabular}{lllll}
\hline Plant growth temperature & Barley & $\begin{array}{l}\text { Brassinolide } \\
\left(\mathrm{pg} \mathrm{g}^{-1} \mathrm{~F} . \mathrm{W} .\right)\end{array}$ & $\begin{array}{l}\text { Castasterone } \\
\left(\mathrm{pg} \mathrm{g}^{-1} \mathrm{~F} . \mathrm{W} .\right)\end{array}$ & $\begin{array}{l}28 \text {-Homocastas- } \\
\text { terone } \\
\left(\mathrm{pg} \mathrm{g}^{-1} \mathrm{~F} . \mathrm{W} .\right)\end{array}$ \\
\hline $20^{\circ} \mathrm{C}$ & Delisa & $145 \pm 30^{\mathrm{a}}$ & $214 \pm 13^{\mathrm{a}}$ & $2214 \pm 474^{\mathrm{a}}$ \\
& $522 \mathrm{DK}$ & $21 \pm 3^{\mathrm{b}}$ & $76 \pm 7^{\mathrm{b}}$ & $1649 \pm 384^{\mathrm{a}}$ \\
$5{ }^{\circ} \mathrm{C}(10$ days $)$ & Delisa & $<L O D$ & $714 \pm 169^{\mathrm{a}}$ & $1940 \pm 218^{\mathrm{a}}$ \\
& $522 \mathrm{DK}$ & $<L O D$ & $358 \pm 75^{\mathrm{b}}$ & $1982 \pm 391^{\mathrm{a}}$ \\
$5{ }^{\circ} \mathrm{C}(21$ days $)$ & Delisa & $<L O D$ & $736 \pm 169^{\mathrm{a}}$ & $8537 \pm 1736^{\mathrm{a}}$ \\
& $522 \mathrm{DK}$ & $<L O D$ & $446 \pm 88^{\mathrm{b}}$ & $6596 \pm 1538^{\mathrm{a}}$ \\
$27{ }^{\circ} \mathrm{C}(3$ days $)$ & Delisa & $<L O D$ & $197 \pm 21^{\mathrm{a}}$ & $870 \pm 189^{\mathrm{a}}$ \\
& $522 \mathrm{DK}$ & $<L O D$ & $74 \pm 6^{\mathrm{b}}$ & $927 \pm 276^{\mathrm{a}}$ \\
$27{ }^{\circ} \mathrm{C}(7$ days $)$ & Delisa & $<L O D$ & $164 \pm 14^{\mathrm{a}}$ & $2437 \pm 282^{\mathrm{a}}$ \\
& $522 \mathrm{DK}$ & $<L O D$ & $91 \pm 17^{\mathrm{b}}$ & $1712 \pm 143^{\mathrm{b}}$ \\
\hline
\end{tabular}

Significant differences between averages $( \pm \mathrm{SE}$ ) for cv. Delisa and 522DK (Student's $t$ test, $P \leq 0.05$ ) for each temperature are indicated by different letters. <LOD below limit of detection 
Table 2 Content of brassinosteroids in the barley cv. Bowman and its mutants BW084 and BW312 growing at $20^{\circ} \mathrm{C}$ and after acclimation at $5{ }^{\circ} \mathrm{C}(10$ and 21 days $)$ and $27^{\circ} \mathrm{C}$ ( 3 and 7 days)

\begin{tabular}{lllll}
\hline Plant growth temperature & Barley & $\begin{array}{l}\text { Brassinolide } \\
\left(\mathrm{pg} \mathrm{g}^{-1} \mathrm{~F} . W .\right)\end{array}$ & $\begin{array}{l}\text { Castasterone } \\
\left(\mathrm{pg} \mathrm{g}^{-1} \mathrm{~F} . \mathrm{W} .\right)\end{array}$ & $\begin{array}{l}28 \text {-Homocastas- } \\
\text { terone } \\
\left(\mathrm{pg} \mathrm{g}^{-1} \text { F.W. }\right)\end{array}$ \\
\hline $20^{\circ} \mathrm{C}$ & Bowman & $102 \pm 21^{\mathrm{b}}$ & $112 \pm 20^{\mathrm{b}}$ & $3149 \pm 497^{\mathrm{a}}$ \\
& BW084 & $<L O D$ & $<L O D$ & $2583 \pm 683^{\mathrm{ab}}$ \\
& BW312 & $269 \pm 43^{\mathrm{a}}$ & $465 \pm 99^{\mathrm{a}}$ & $1630 \pm 116^{\mathrm{b}}$ \\
$5{ }^{\circ} \mathrm{C}(10$ days $)$ & Bowman & $<L O D$ & $268 \pm 56^{\mathrm{b}}$ & $3816 \pm 906^{\mathrm{a}}$ \\
& BW084 & $<L O D$ & $<L O D$ & $2523 \pm 255^{\mathrm{b}}$ \\
& BW312 & $<L O D$ & $869 \pm 170^{\mathrm{a}}$ & $2799 \pm 469^{\mathrm{ab}}$ \\
$5{ }^{\circ} \mathrm{C}(21$ days $)$ & Bowman & $<L O D$ & $368 \pm 97^{\mathrm{b}}$ & $11,175 \pm 2014^{\mathrm{a}}$ \\
& BW084 & $<L O D$ & $<L O D$ & $7234 \pm 1544^{\mathrm{b}}$ \\
$27{ }^{\circ} \mathrm{C}(3$ days $)$ & BW312 & $<L O D$ & $1255 \pm 278^{\mathrm{a}}$ & $7690 \pm 1056^{\mathrm{b}}$ \\
& Bowman & $<L O D$ & $119 \pm 8^{\mathrm{b}}$ & $1090 \pm 230^{\mathrm{a}}$ \\
& BW084 & $<L O D$ & $<L O D$ & $807 \pm 180^{\mathrm{a}}$ \\
$27^{\circ} \mathrm{C}(7$ days $)$ & BW312 & $<L O D$ & $343 \pm 83^{\mathrm{a}}$ & $1101 \pm 313^{\mathrm{a}}$ \\
& Bowman & $<L O D$ & $145 \pm 7^{\mathrm{b}}$ & $2935 \pm 605^{\mathrm{a}}$ \\
& BW084 & $<L O D$ & $<L O D$ & $1504 \pm 277^{\mathrm{b}}$ \\
& BW312 & $<L O D$ & $590 \pm 99^{\mathrm{a}}$ & $1974 \pm 230^{\mathrm{b}}$ \\
\hline
\end{tabular}

Significant differences between averages $( \pm \mathrm{SE})$ for cv. Bowman and its mutants (Duncan's test, $P \leq 0.05$ ) for each temperature are indicated by different letters. $<$ LOD below limit of detection
BW084, brassinolide was below the detection limit. The content of brassinolide in BW312 was twice as high as in Bowman, which was accompanied by (and probably resulted from) an elevated level of castasterone in this mutant. Generally, it is noticeable that longer cold acclimation increased the level of castasterone and 28-homocastasterone in all tested mutants and wild types, sometimes even by a few times in comparison to that at $20^{\circ} \mathrm{C}$. This is the same tendency as earlier noted in cold acclimated winter rye (Pociecha et al. 2016) and winter wheat (Janeczko and Oklestkova, unpublished data), so probably the phenomenon is characteristic, at least, for cereals. On the other hand, in plants acclimated to $27{ }^{\circ} \mathrm{C}$ ( 7 days), the content of BR was maintained at a similar level to that at $20{ }^{\circ} \mathrm{C}$ or was even lower.

\section{Auxins}

Auxin and BR interplay is reviewed by Zhang et al. (2009), but little is known about endogenous auxin homeostasis in relation to BR deficiency or disturbances in BR signalling. The following auxins were detected in our experiment: IAA, IBA, oxIAA and IAAMe (Fig. 1a-j). At $20^{\circ} \mathrm{C}$ and at $5{ }^{\circ} \mathrm{C}$, the content of IAA in the wild-type Delisa and 522DK was at a similar level, whereas at $27{ }^{\circ} \mathrm{C}$ the level of this auxin was increased in 522DK. In the wild-type Bowman and its mutants, the content of IAA remained at a similar level regardless of the temperature conditions. Our earlier studies (Janeczko et al. 2016; Gruszka et al. 2016a) have shown no evidence that barley BR-mutants have increased IAA content, which is generally in agreement with current findings. Simultaneously, the exogenous application of brassinolide on Arabidopsis (Col-0) and mutant det 2 plants induced IAA5 and IAA 19 gene expression gradually and continuously, but it did not increase the endogenous level of IAA (Nakamura et al. 2003). IBA content in all our tested mutants was similar as in the wild types regardless of the growth temperature. Mutant 522DK had a lower level of oxIAA (50-70\%) compared to Delisa at all temperatures. In the BW084 and BW312 mutants (compared to Bowman), a similar slight tendency was observed, but statistical significance was only achieved at $5{ }^{\circ} \mathrm{C}$. To the best of our knowledge, our analysis has revealed the auxin metabolite oxIAA in barley for the first time. OxIAA is considered to be inactive, or only a slightly active product of IAA oxidation in the catabolic pathway of this hormone (Reinecke and Bandurski 1983; Pěnčík et al. 2013). It has been established that the oxIAA content increases in response to an increased auxin level (Pěnčík et al. 2013). The lower content of oxIAA in our barley mutants may theoretically mean that the level of IAA was maintained at a normal (defined for wild types) level due to the mechanism of the limited deactivation of IAA. This suggests a role for BR in auxin catabolism at which a lower level of BR limits the deactivation of auxins.

IAA can be also conjugated, for example, to amino acids or sugars or converted to methyl IAA ester (IAAMe) (Qin et al. 2005). The role of such conjugates is primarily to store or transport the auxins as well as to detoxify any excess IAA and to protect free acids from peroxidative degradation (LeClere et al. 2002). Our studies are the first to report the presence of IAAMe in barley plants with disturbances in the BR biosynthesis and signalling. In our work, at $20^{\circ} \mathrm{C}$, the content of IAAMe was lower in the 522DK mutant than 
in Delisa (by about 30\%), but it was increased in BW084 (20\%) compared to Bowman. In BW312, the content of IAAMe was lower by $70 \%$ compared to Bowman. At $5{ }^{\circ} \mathrm{C}$ and $27{ }^{\circ} \mathrm{C}$, no changes were observed for this compound between the mutants and their wild types. According to Qin et al. (2005), exogenously applied IAAMe had stronger effects than free IAA, which indicates that IAA methylation may have a role in regulating the IAA activities. The complex regulation of the IAAMe accumulation is shown by the opposite effect that was obtained at $20{ }^{\circ} \mathrm{C}$ for the two BR-biosynthesis mutants with a different mutation type (and different BR level). Simultaneously, the dramatically lower content of IAAMe in the BW312 mutant has provided information about the role of BR signalling in regulating the accumulation of this compound. It is known that BR regulate auxin signalling. BZR1 (Brassinazole Resistant1a major transcription factor regulating the BR-dependent gene expression) interacts with the ARF proteins (Auxin Response Factors-the class of transcriptional regulators) to target multiple auxin signalling components and the genes that are involved in the auxin metabolism (Tian et al. 2018).

The total auxin content decreased in the 522DK mutant at $20^{\circ} \mathrm{C}$ and $5{ }^{\circ} \mathrm{C}$ (but not at $27^{\circ} \mathrm{C}$ ) compared to the wild-type Delisa. In the Bowman-derived mutants, the total auxin content was significantly decreased only in the mutant BW312 at a temperature of $20{ }^{\circ} \mathrm{C}$ but remained unchanged in all other samples.

To summarise, a BR-deficit or disrupted signalling of BR have no direct impact on the accumulation of particular active auxins but does affect the accumulation of auxins in methylated or oxidised forms, thus suggesting a role for BR in auxin metabolism in barley.

\section{Cytokinins}

We were able to detect $\mathrm{t}-\mathrm{Z}, \mathrm{c}-\mathrm{Z}, \mathrm{DHZ}$ and $\mathrm{t}-\mathrm{ZOG}$ in the barley (Fig. 2a-j). According to the literature, exogenous application of BR on plants may influence the accumulation of cytokinins (Kudryakova et al. 2013). Brassinolidetreated transgenic A. thaliana plants (carrying the GUS reporter linked to the promoter for the ARR 5 gene of primary response to cytokinins) had an increased cytokinin level, by about $48 \%$, in their leaves compared to untreated plants (Kudryakova et al. 2013). In the leaves of barley treated with 24-epibrassinolide under the white light of a fluorescent lamp, the content of $\mathrm{tZ}, \mathrm{cZ}$ and DHZ increased by about 60,66 and $150 \%$, respectively, whereas the content of t-ZOG decreased (43\%) (Efimova et al. 2017). Taking this into consideration, we have assumed that in our experiment the amount of cytokinins could be lower, especially in the BR-deficient mutants. Generally, the assumptions were verified in plants with mutation in the $H \nu C P D$ gene growing at temperatures of $5^{\circ} \mathrm{C}$ and $20^{\circ} \mathrm{C}$. At $20^{\circ} \mathrm{C}$, BW084 had a lower content of individual cytokinins and total cytokinins than Bowman, although in the cases of t-Z and t-ZOG only a statistically insignificant tendency was observed. In BW084 at $5{ }^{\circ} \mathrm{C}, \mathrm{c}-\mathrm{Z}$ and t-ZOG content was only lowered a few percent. The decrease in cytokinins in the BR-deficient mutants was not observed in plants with the mutation in the $H v D$ $W A R F$ gene. The only exception was $14 \%$-higher content of DHZ in the 522DK mutant compared to Delisa, observed at $5{ }^{\circ} \mathrm{C}$. Interestingly, in our earlier studies, this mutation was correlated with a lowered cytokinin level (Janeczko et al. 2016). That experiment was, however, conducted under different conditions, at natural spring light in a hall without sidewalls and with a transparent (foil) roof. We have suspected that the different conditions of plant growth in the previous and present experiments, particularly the effect of light, are the cause of these differences. The role of light in regulating cytokinin homeostasis and physiological effects is well known (Kudryakova et al. 2013; Roman et al. 2016; Dobisova et al. 2017).

Finally, a marked decrease in the cytokinin content in the BR-signalling defective mutant was observed suggesting a link between BR signalling and cytokinin biosynthesis pathways in barley. At $20^{\circ} \mathrm{C}$ and $5{ }^{\circ} \mathrm{C}$, BW312 had a lower content of all cytokinins (by average about $20 \%$ ) in comparison to Bowman, although, in the case of $\mathrm{t}-\mathrm{Z}$ statistical significance was not proven. According to Kudryakova et al. (2013), BR may be involved in regulating the genes in the cytokinin-signalling pathway via an increase in the cytokinin levels.

\section{Gibberellins}

Interplay between BR and gibberellins is rather complicated, multilevel and depends on species or growth conditions (Jager et al. 2005; Tong et al. 2014; Unterholzner et al. 2015). Arabidopsis mutants deficient in BR signalling had impaired biosynthesis of bioactive GA, which is connected with defective expression of the GA-biosynthetic genes (Unterholzner et al. 2015). According to Jager et al. (2005), BR negatively regulated GA20 levels in pea. GA20 levels were affected by the BR content, but this did not result in clear alterations in the level of the bioactive GA1. On the other hand, the studies of Tong et al. (2014) have shown that BR greatly induces the expression of D18/GA3ox-2, one of the GA biosynthetic genes, which caused an increase in the bioactive GA1 level in rice seedlings.

In our studies, the following gibberellins were detected: GA1, GA3, GA4, GA5 and GA6 (Fig. 3a-1). These studies have shown that the level of BR may be important in barley tissue and, more generally, the abnormalities at different stages of the BR biosynthetic pathways, which are catalyzed by the mutated enzymes (HvCPD in BW084 and HvDWARF in 522DK) seem to affect the accumulation of 
Fig. 2 Content of cytokinins in the barley cv. Delisa and its 522DK mutant (a, c, e, $\mathbf{g}, \mathbf{i})$ and in the barley cv. Bowman and its BW084 and BW312 mutants $(\mathbf{b}, \mathbf{d}, \mathbf{f}, \mathbf{h}, \mathbf{j})$ at $20^{\circ} \mathrm{C}$ and after acclimation at $5{ }^{\circ} \mathrm{C}$ and $27^{\circ} \mathrm{C}$. The mean values are shown with bars that represent SE. Significant differences between cv. Delisa and 522DK-Student's $t$ test; between cv.

Bowman and its mutants-Duncan's test, $(P \leq 0.05)$ for each temperature are indicated by different letters
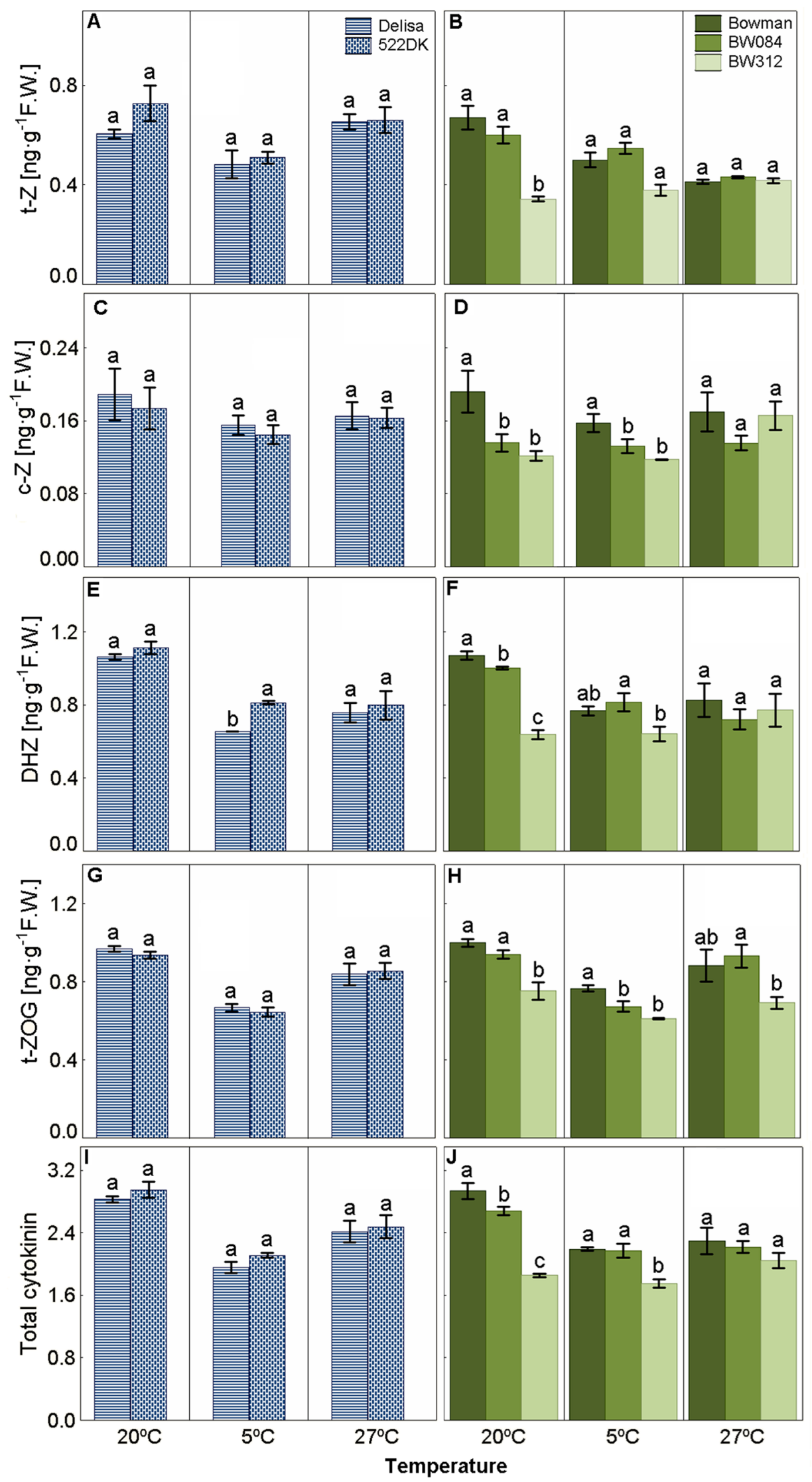
Fig. 3 Content of gibberellins in the barley cv. Delisa and its 522DK mutant (a, c, $\mathbf{e}, \mathbf{g}, \mathbf{i}, \mathbf{k})$ and in the barley $\mathrm{cv}$. Bowman and its BW084 and BW312 mutants (b, d, f, h, j, l) at $20^{\circ} \mathrm{C}$ and after acclimation at $5{ }^{\circ} \mathrm{C}$ and $27^{\circ} \mathrm{C}$. The mean values are shown with bars that represent SE. Significant differences between the cv. Delisa and 522DK-Student's $t$ test; between cv. Bowman and its mutants-Duncan's test, $(P \leq 0.05)$ for each temperature are indicated by different letters

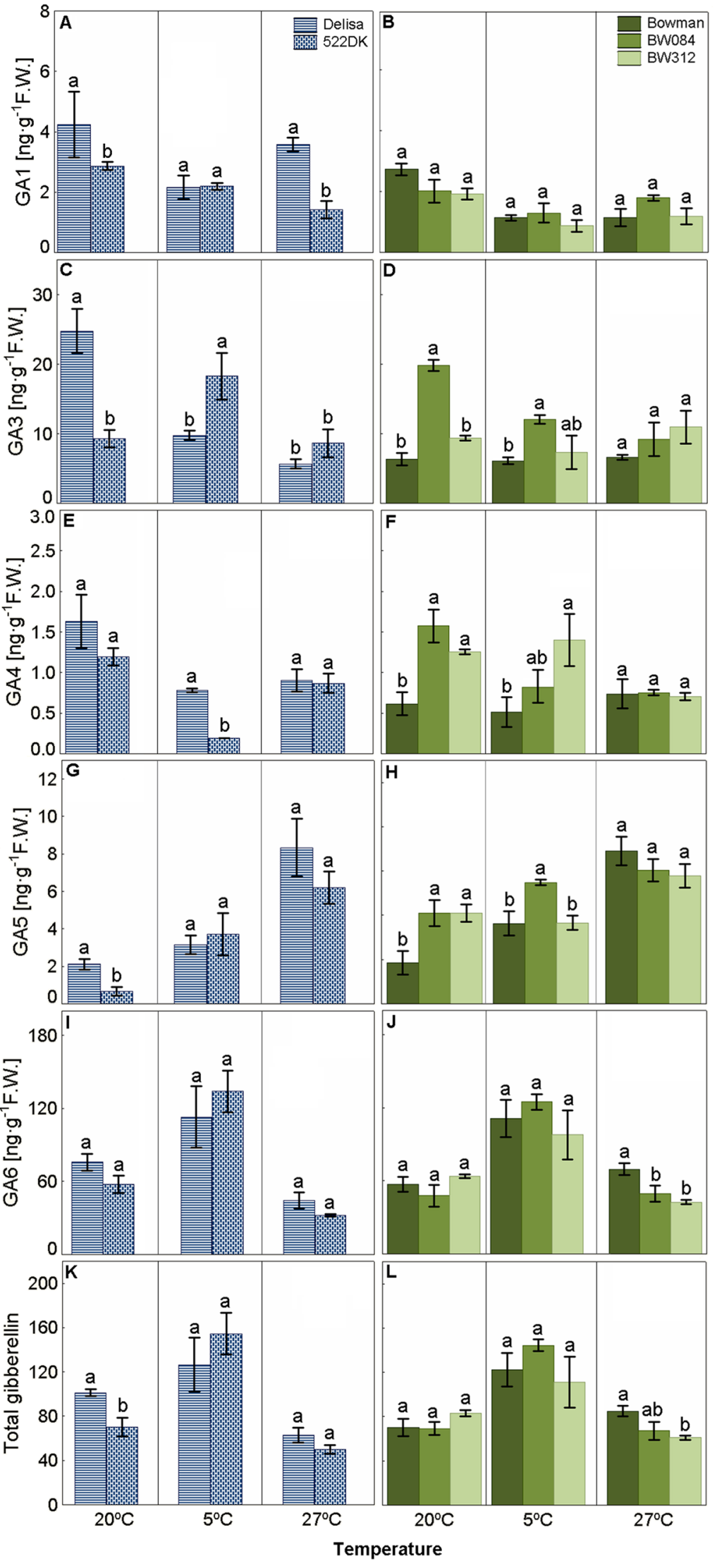


various representatives of gibberellins. The opposite effects were observed for the mutants carrying substitutions in the $H v C P D$, and $H v D W A R F$ genes, especially in terms of GA3, GA4 and GA5. Especially at $20^{\circ} \mathrm{C}$ and partly at $5{ }^{\circ} \mathrm{C}$ (GA4, GA5), the content of the aforementioned gibberellins decreased in 522DK whereas they increased in BW084. Interestingly, at $5{ }^{\circ} \mathrm{C}$, GA3 content increased in both mutants. As for GA3, this compound was discovered in the fungus Gibberella fujikuroi (Hedden and Sponsel 2015), but later its occurrence was proven in plants, for example, Fagus sylvatica, Pinus pinaster, Malus hupehensis, and Triticum aestivum (Fernández et al. 1997; Delatorre et al. 2017; Mao et al. 2017; Janeczko et al. 2018). Mao et al. (2017) even found that treatment of Malus hupehensis apple seedlings with brassinolide decreases GA3 content in comparison to untreated plants. No changes were noted in the GA3 level in BW312 in comparison to Bowman.

No differences were observed in the GA6 content regardless of the temperature conditions between 522DK and Delisa (Fig. 3i). The same was observed for Bowman and its mutants at temperatures of $20^{\circ} \mathrm{C}$ and $5{ }^{\circ} \mathrm{C}$, but at $27^{\circ} \mathrm{C}$ the content of GA6 was significantly lower in both mutants than in Bowman (Fig. 3j).

The total gibberellin content was about $30 \%$ lower in the 522DK mutant compared to the wild type at $20^{\circ} \mathrm{C}$ only. As for Bowman and its mutants, the total gibberellin content was only lower in the mutant BW312 compared to Bowman (at $27^{\circ} \mathrm{C}$ ).

Different levels of particular BR compounds, which are caused by mutations in different genes ( $H v C P D$ and $H v D$ $W A R F$ ) that encode enzymes catalyzing different steps of the BR biosynthetic pathway, are probably significant for modifying gibberellin accumulation in different ways. Changes in the content of some of the gibberellins studied in the BR-signalling defective mutant also suggest a connection between the BR signalling and the gibberellin biosynthetic pathways in barley.

\section{Abscisic Acid}

Abscisic acid (ABA) and its conjugate form ABAGlc were detected in our study (Fig. 4a-d). According to the literature, exogenous BR increase the accumulation of this stress hormone at both low and high temperatures, which was found in Chorispora bungeana cell cultures (Liu et al. 2011), algal cells (Bajguz 2009) and Brassica napus seedlings (Kurepin et al. 2008). So, we have presumed that the BR-deficiency characteristic for the 522DK and BW084 mutants will be correlated with a lowered content of ABA. In fact, our earlier studies on barley, grown outside and under natural light conditions, have shown that free ABA content was decreased in the 522DK mutant compared to the wild type Delisa in optimally watered plants and, especially, in drought-stressed plants (Janeczko et al. 2016). Here, in an experiment conducted in the artificial light of sodium lamps, the effect was not observed in 522DK (Fig. 4a). The content of ABAGlu was also unchanged in this mutant when compared to Delisa and regardless of the growth temperature (Fig. 4c). In BW084, ABAGlu was also unchanged, whereas free ABA content was lowered only in plants at $5{ }^{\circ} \mathrm{C}$ (Fig. 4b, d). In our opinion, similar to cytokinins, the light spectrum (and perhaps intensity) plays an important role in the biosynthesis of ABA. It has been described that ABA concentration is regulated/elevated strongly, for instance, by the UV-B radiation that is present in the natural light spectrum (Tossi et al. 2009). It seems that the role of light conditions on the hormonal homeostasis of the barley BR mutants should be more closely studied in the future.

On the other hand, Hu and Yu (2014) reported an interplay between ABA and BR signalling (BR repressed the ABA signalling) in Arabidopsis thaliana L., whereas, according to Wang et al. (2018), ABA inhibits BR signalling. Our work has also suggested a connection between ABA content and BR signalling, although it depends on the temperature during plant growth. Especially interesting results were observed at $20^{\circ} \mathrm{C}$, where the BR-signalling mutant (BW312) simultaneously accumulated a lower ABA content but an increased content of the abscisic acid glucosyl ester (ABAGlc) (Fig. 4b, d). ABAGlc is a hydrolysable ABA conjugate of which deconjugation enables the formation of free $\mathrm{ABA}$ in response to stress conditions, and this, in turn, enables ABAGlc to participate in the maintenance of ABA homeostasis (Burla et al. 2013). In our work, the phenomenon observed at a temperature of $20^{\circ} \mathrm{C}$ was not observed at $5{ }^{\circ} \mathrm{C}$ or $27^{\circ} \mathrm{C}$, possibly because, under these more stressful temperatures, ABAGlc was more intensively mobilised to form free ABA to obtain an amount as high as is only possible for the BW312 mutant.

\section{Salicylic Acid}

The literature describing interplay between SA and BR is scarce. An artificial increase of the BR level via exogenous application of 24-epibrassinolide to perennial ryegrass, combined with low temperature conditions $\left(4^{\circ} \mathrm{C}, 6\right.$ weeks) did not cause statistically significant changes in the salicylic acid content (Pociecha et al. 2017). On the other hand, we did not observe any changes in the SA level in either BR-deficient mutant at $20^{\circ} \mathrm{C}$ and $5{ }^{\circ} \mathrm{C}$ (Fig. 4e, f). The BR deficiency was accompanied by an increase in the SA content only in the BW084 mutant at $27{ }^{\circ} \mathrm{C}$ (Fig. 4f). This, once again, suggests the importance of the stage in the BR biosynthesis pathway at which the deficiency occurs (the mutations in the $H v C P D$ and $H v D W A R F$ genes), which are connected with the difference in 
Fig. 4 Content of ABA, ABAGlc and SA in the barley cv. Delisa and its 522DK mutant $(\mathbf{a}, \mathbf{c}, \mathbf{e})$ and in the barley cv. Bowman and its BW084 and BW312 mutants $(\mathbf{b}, \mathbf{d}, \mathbf{f})$ at $20^{\circ} \mathrm{C}$ and after acclimation at $5{ }^{\circ} \mathrm{C}$ and $27^{\circ} \mathrm{C}$. The mean values are shown with bars that represent SE. Significant differences between the $\mathrm{cv}$. Delisa and 522DK-Student's $t$ test; between the cv. Bowman and its mutants-Duncan's test, $(P \leq 0.05)$ for each temperature are indicated by different letters
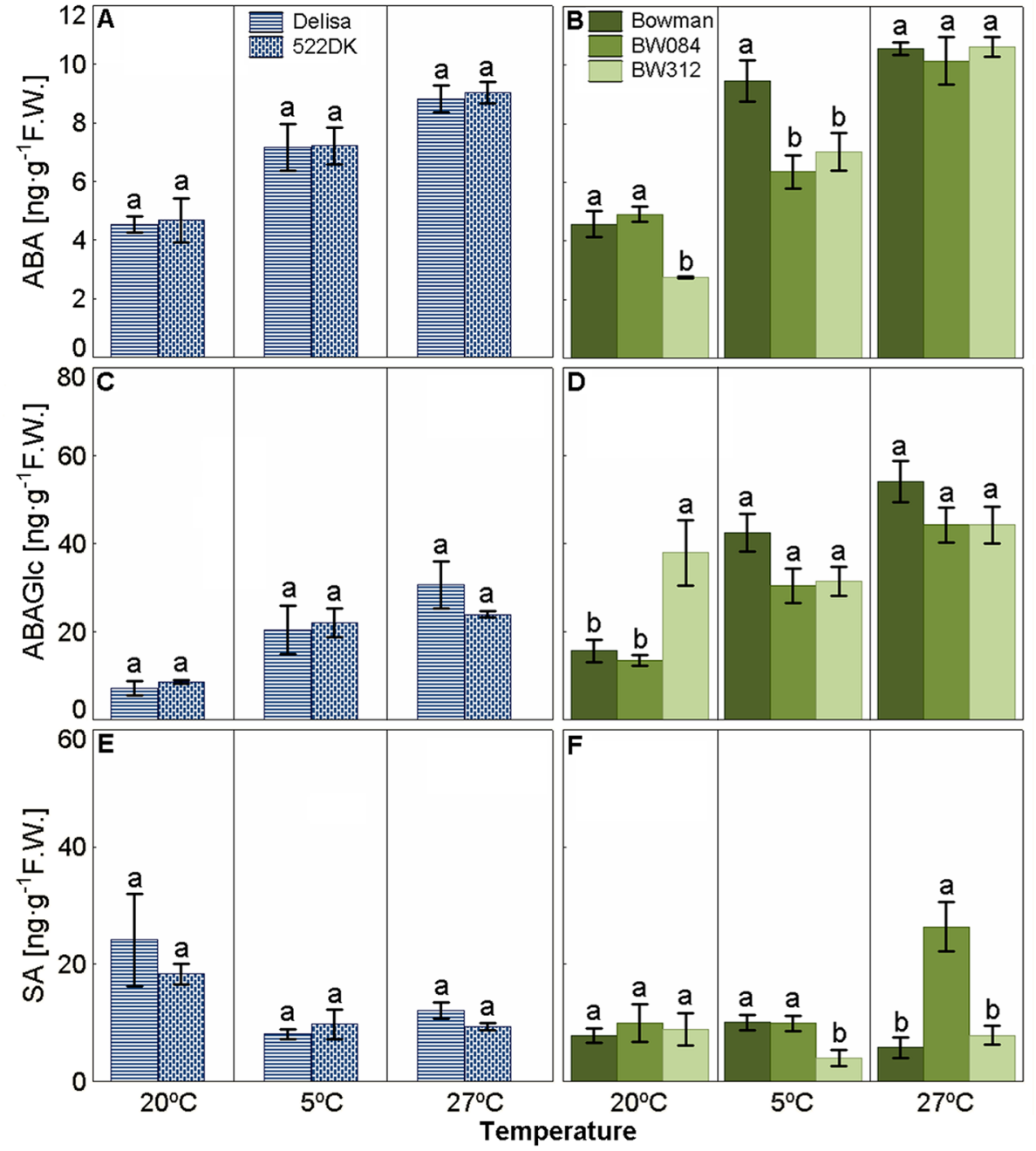

the BR content, and the effect of the temperature during plant growth on the possibility of the SA-BR crosstalk in barley.

Divi et al. (2010) showed some links between BR and SA in experiments on temperature-stressed plants of Arabidopsis. Also, in our study the content of SA was lower in the BRsignalling mutant at $5^{\circ} \mathrm{C}$, thereby suggesting some connection between the BR- and SA-signalling pathways also in barley.

Supplementary Materials: Table S2 provides an insight into the complicated hormonal homeostasis in the BR barley mutants. The table summarises the effect of mutations in the genes participating in the BR biosynthetic or signalling pathways on phytohormone accumulation, and dependence on the ambient temperature.

\section{Characterisation of the PSII Efficiency of the Barley BR Mutants Grown at $20^{\circ} \mathrm{C}$, and then Acclimated to $5^{\circ} \mathrm{C}$ and $27^{\circ} \mathrm{C}$}

Many studies have shown that exogenous BR stimulate plant photosynthesis - the efficiency of both light and dark reactions (for a review see Holá 2011). Analysis of the fast kinetics of chlorophyll $a$ fluorescence in high temperature-stressed barley revealed that exogenous BR can increase PSII performance (Janeczko et al. 2011), which is why we have presumed that a BR deficit may have a negative influence on PSII functioning. However, analysis of the fast kinetic of fluorescence of chlorophyll $a$ revealed that BR-deficient barley mutants $(522 \mathrm{DK}$, BW084) had a better performance of the light reactions of photosynthesis that are related to PSII (Fig. 5a-j). This was generally expressed by elevated values of the performance index (P.I. ${ }_{A B S}$ ) when compared to the respective wild type cultivars (Fig. 5i, j). Detailed analysis of the phenomenological fluxes (ABS/CSm, TRo/CSm, ETo/CSm, DIo/CSm) has revealed that, in comparison to the respective wild type cultivars, all the BR-deficient mutants had significantly lower losses of energy (DIo/CSm). Simultaneously, the energy flux for electron transport (ETo/CSm) was increased at $20^{\circ} \mathrm{C}$ in the 522DK and BW084 mutants and at $5{ }^{\circ} \mathrm{C}$ - especially in the mutant 522DK. At $27^{\circ} \mathrm{C}$, ETo/CSm was unchanged in 522DK or slightly lower in BW084. The phenomenon took place in 
Fig. 5 Efficiency of PSII of the barley cv. Delisa, 522DK mutant, cv. Bowman, BW084 and BW312 mutants at $20^{\circ} \mathrm{C}$ and after acclimation at $5{ }^{\circ} \mathrm{C}$ and $27^{\circ} \mathrm{C}$ as expressed by phenomenological fluxes: $\mathbf{a}, \mathbf{b}$ the absorption of energy ABS/CSm; c, $\mathbf{d}$ energy flux for trapping $\mathrm{TRo} / \mathrm{CSm}$; e, f energy flux for electron transport (ETo/CSm); $\mathbf{g}, \mathbf{h}$ energy dissipation DIo/ $\mathrm{CSm} ; \mathbf{i}, \mathbf{j}$ performance index (P.I. ${ }_{\text {ABS }}$ ). The mean values are shown with bars that represent SE. Significant differences between cv. Delisa and 522DK - Student's $t$ test; between cv. Bowman and its mutants-Duncan's test, $(P \leq 0.05)$ for each temperature are indicated by different letters

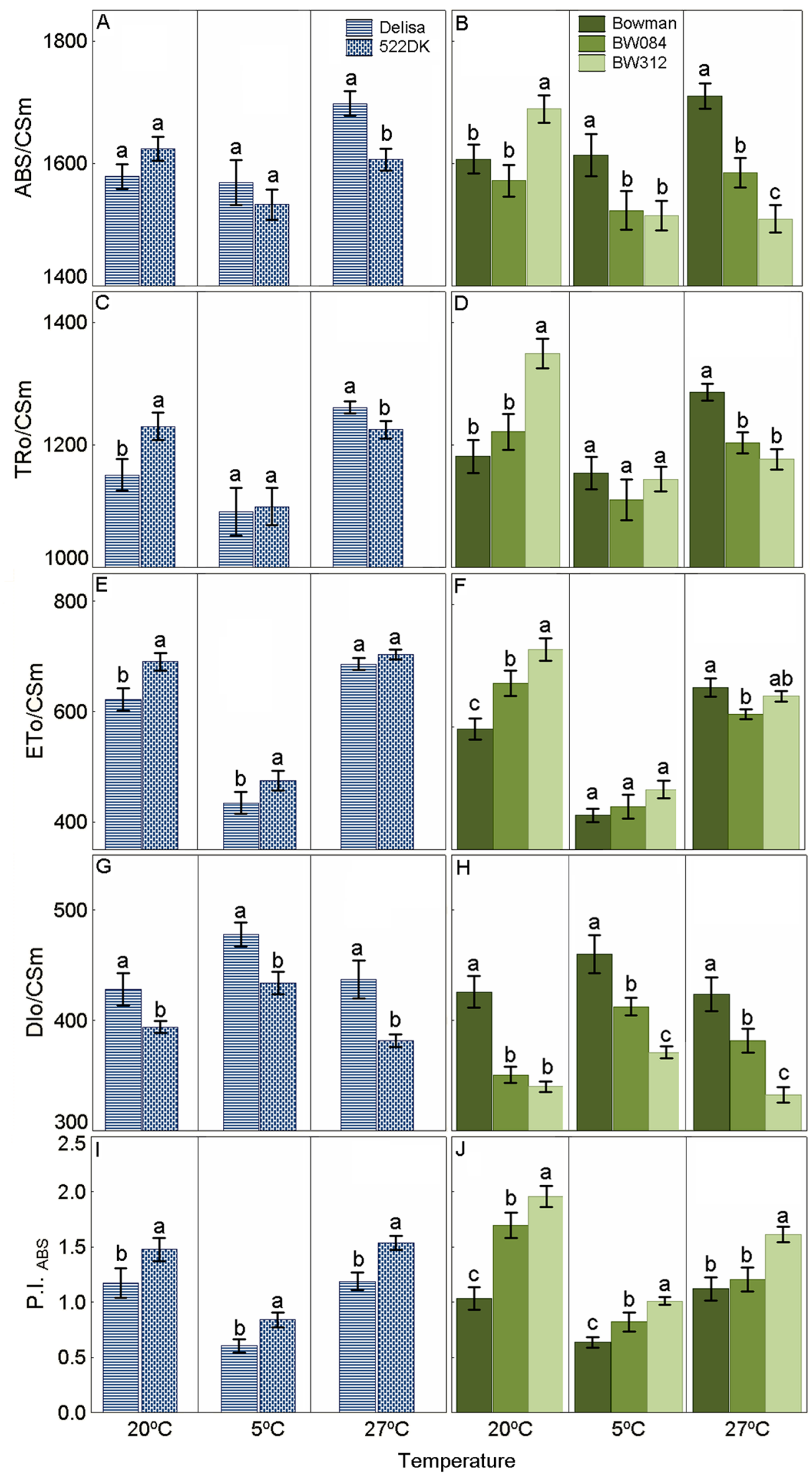


the situation when energy absorption by antennas (ABS/CSm) was similar or even decreased in the mutants in comparison to their wild type cultivars, which has provided information about more efficient energy conservation in the BR-deficient mutants.

Results obtained in the present experiment, which was carried out under artificial light are in accordance with our earlier studies, in which optimally watered BR-deficient mutants 522DK and 527DK grown under natural light conditions also had better performance of the PSII reactions (Janeczko et al. 2016). Although the chlorophyll content was lower in the mutants, the carotenoid level was higher, which in this case might have a positive effect on energy capture and PSII efficiency (Janeczko et al. 2016). As for other data from the literature, there are only a few studies characterising the PSII efficiency in plants with changed levels of endogenous BR. Data obtained by Wu et al. (2008) seem to contradict our observations because in transgenic rice with an increased BR accumulation, an increased maximum quantum yield of the primary photochemistry of PSII $\left(F_{\mathrm{v}} / F_{\mathrm{m}}\right)$ was observed when compared to the wild type (Wu et al. 2008). On the other hand, these results seemed to be dependent on the light intensity and the best effect was achieved at $150 \mu \mathrm{mol} \mathrm{m} \mathrm{m}^{-2} \mathrm{~s}^{-1}$. Anyway, according to $\mathrm{Wu}$ et al. (2008), the mechanism of BR action on the light reactions of photosynthesis remains unknown. The authors suspect that the repression of expression of genes encoding the U-box ubiquitin ligase and the chloroplast protease (observed in the microarray data) might have prolonged the half-life of some of the photosynthetic proteins.

In our experiment, a slightly different situation was observed in the case of the BR signalling mutant BW312. BW312, when grown at $20^{\circ} \mathrm{C}$, had values of energy absorption by antennas (ABS/CSm) higher than the wild type Bowman, which allowed plants to reach the highest of all experiment values observed of TRo/CSm, ETo/CSm and P.I. ${ }_{\mathrm{ABS}}$. Interestingly, at the end of acclimation at $5{ }^{\circ} \mathrm{C}$ and $27^{\circ} \mathrm{C}$, this mutant had an ABS/CSm much lower than the wild type but maintained ETo/CSm on a level similar to Bowman, probably due to much lower energy loses (DIo/CSm). All this allowed

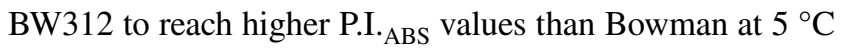
and $27^{\circ} \mathrm{C}$.

To conclude, our work has allowed characterisation of the PSII efficiency in the BR-deficient and signalling-defective mutants, but the role of BR content and BR signalling for functioning of the light reactions of photosynthesis will require further and more detailed proteomic and genetic studies.

\section{Tolerance of the Barley BR Mutants to Frost and High Temperatures}

\section{Frost Tolerance}

After exposure of all tested mutants and their wild types to $-6{ }^{\circ} \mathrm{C}$, plant regrowth was very effective and reached from eight to nine points on the Larsen scale (Fig. 6a, b). After exposure to a temperature of $-8{ }^{\circ} \mathrm{C}$, plants of Delisa cultivar and the 522DK mutant had a similar level of regrowth of about three points on the Larsen scale. After the same temperature treatment of Bowman, the plants had regrowth at a level of about eight points, whereas the BW084 and BW312 mutants were characterised with regrowth at about four and six points, respectively. The results of the regrowth test have shown that both these mutants suffered higher damage at $-8{ }^{\circ} \mathrm{C}$ than the wild-type Bowman. We have presumed that the $\mathrm{BR}$ in plants are involved in regulating their acclimation to low temperatures, thus BR-deficient and BR-signalling mutants should be less tolerant to low temperatures, compared to the wild types. Our presumption was made based on our earlier studies (Pociecha et al. $2016,2017)$ that showed increased frost tolerance after an application of exogenous BR in winter rye and perennial ryegrass, together with an increased accumulation of castasterone after cold acclimation (cold hardening) and before frost exposition (Pociecha et al. 2016). Our hypothesis has been verified positively only partly. The castasterone accumulation in the BW084 mutant was below the detection limit and was accompanied by a decrease in its tolerance to frost. On the other hand, the BR deficiency in 522DK did not cause the effect of lowered frost tolerance, but it should be noted that in this mutant castasterone was still present at the level of $446 \mathrm{pg} \mathrm{g}^{-1}$ F.W. Further, we suspect that 28-homocastasterone may be more important for plant frost tolerance than castasterone. Our parallel experiments on winter wheat (Janeczko and Oklestkova, unpublished data) have shown that after cold acclimation a higher content of 28-homocastasterone was characteristic for more frost-tolerant cultivars of winter wheat. The correlation was not so clear for castasterone. In the present experiment on barley the Delisa cultivar was less frost-tolerant than Bowman because its regrowth after $-8^{\circ} \mathrm{C}$ was at three points, whereas for Bowman it reached seven points (Fig. 6a, b). Simultaneously, after acclimation at $5{ }^{\circ} \mathrm{C}, 28$-homocastasterone in Delisa was at the level of $8537 \mathrm{pg} \mathrm{g}^{-1}$ F.W., whereas in Bowman it reached $11,175 \mathrm{pg} \mathrm{g}^{-1}$ F.W. The content of 28-homocastasterone was not different in the 522DK mutant in comparison with Delisa and, simultaneously, plants had similar regrowth after $-8{ }^{\circ} \mathrm{C}$. The situation is different in Bowman and BW084, where the mutant had a significantly lower content of 28-homocastasterone than Bowman and simultaneously weaker regrowth after exposure to $-8^{\circ} \mathrm{C}$. 
Fig. 6 Tolerance of the barley cv. Delisa, 522DK mutant, the cv. Bowman, BW084 and BW312 mutant to frost $(\mathbf{a}, \mathbf{b})$ and high temperatures $(\mathbf{c}-\mathbf{h})$. $\mathbf{a}, \mathbf{b}$ average regrowth; $\mathbf{c}, \mathbf{d}$ leaf blade damage; e, f photosynthesis efficiency of PSII measured as performance index (P.I. ${ }_{\mathrm{ABS}}$ ); g, h membrane permeability. The mean values are shown with bars that represent SE. Significant differences between the cv. Delisa and 522DK Student's $t$ test; between cv. Bowman and its mutants-Duncan's test, $(P \leq 0.05)$ for each temperature are indicated by different letters
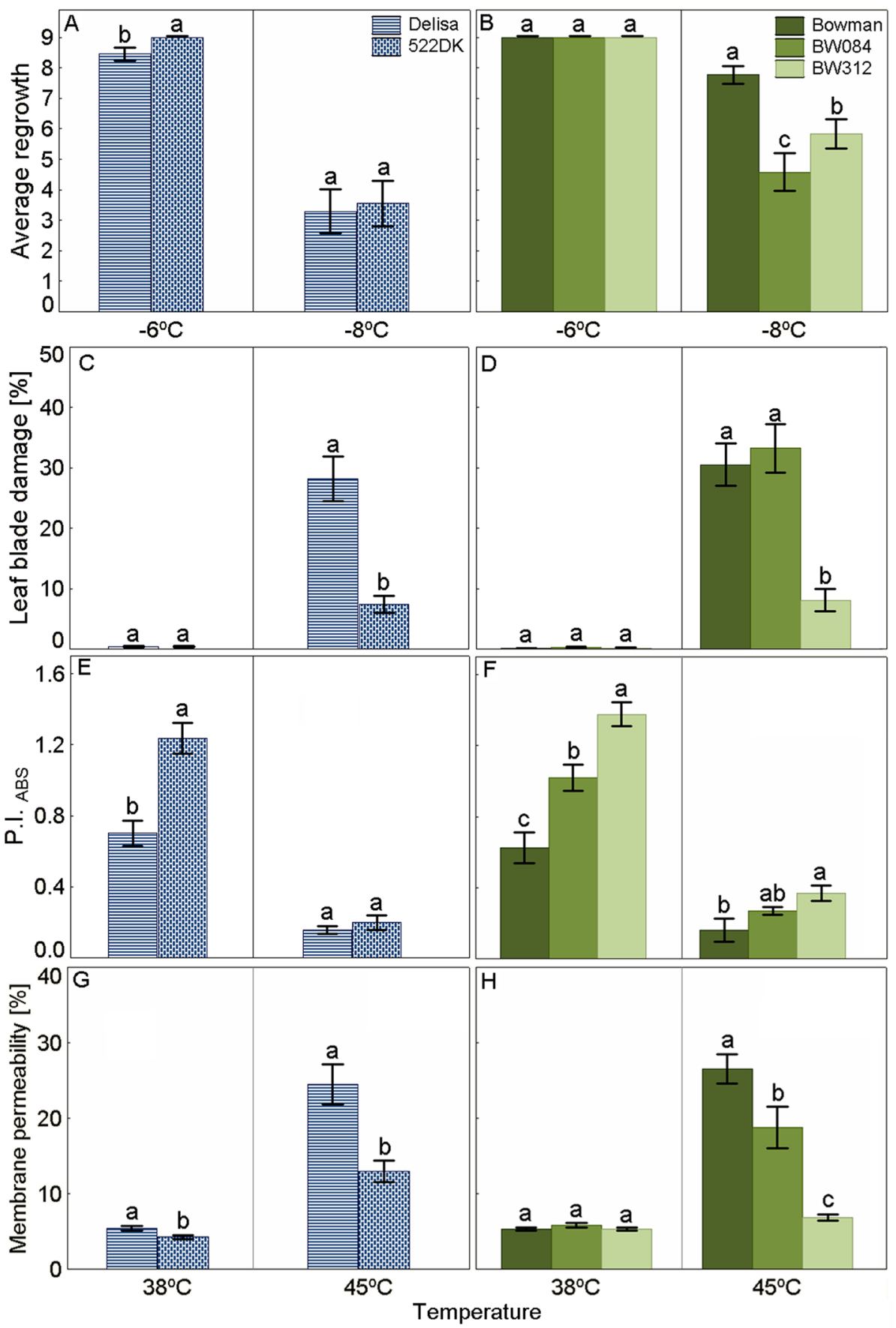

Interestingly, regrowth of the BR-signalling mutant BW312 was little better than BW084, although it was still weaker than in Bowman. BW312 accumulated a very high level of castasterone and it is likely that, in this case, this steroid positively influenced frost tolerance although via an unknown mechanism. Steroids of this kind may interact with cell membranes and stabilise them, especially at low temperatures (Li et al. 2012; Filek et al. 2017), however this requires further studies. As mentioned, BW312 had better survival after frost than BW084 but still lower than Bowman. This phenomenon is probably connected to the BR-signalling disturbances and this finding is in accordance with results published by Eremina et al. (2016). Eremina et al. (2016) studied the role of BR in the process of plant hardening to frost on Arabidopsis thaliana L. mutants with impaired BR signalling. The BR-signalling mutants bril-301 and bril1 had a decreased tolerance to frost. According to these authors, BR improved the frost tolerance of plants by regulating the expression of $C O R$ (cold-responsive) genes. The BR-hypersignalling line 35S:BRII-GFP (BRIloe) mutant 
showed a higher frost tolerance and higher accumulation of the COR15A, COR15B, COR47, COR78 transcripts.

Finally, our experiment has provided knowledge about the hormonal homeostasis in barley that has been cold acclimated (hardened) before frost treatment. Among the results from the hormone analyses, the results for the $\mathrm{ABA}$ accumulation seem to be the most important, as they may explain the differences in frost tolerance between our tested genotypes. ABA is a well-known factor whose increase is correlated with low temperature-stress conditions (Welbaum et al. 1997; Gusta et al. 2005; Janeczko et al. 2018) and is considered to be a hormone, which protects plants against freezing (Veisz et al. 1996). An accumulation of higher amounts of ABA correlates with low temperature resistance in maize (Janowiak et al. 2003). In our experiment, the Delisa cultivar, which is more sensitive to frost, accumulated less ABA in the acclimation process at $5{ }^{\circ} \mathrm{C}$ than the more tolerant cultivar (Bowman). In addition, the ABA content in the 522DK mutant was no different than that of the wildtype Delisa. This corresponds with the same cold tolerance in Delisa and 522DK. In the case of Bowman, both of its mutants were less tolerant to frost and, at the same time, accumulated less ABA than Bowman. These results have painted a picture of the relationship between frost tolerance and the level of BR and ABA accumulation in barley.

\section{High Temperature Tolerance}

We have presumed that BR in plants are involved in regulating their acclimation to high temperature, thus BR-deficient and BR-signalling mutants should be less tolerant to high temperatures when compared to the wild types. Unexpectedly, all the mutants show a higher tolerance to high temperatures than their respective wild types.

After exposure to a temperature of $38{ }^{\circ} \mathrm{C}$, leaf blade damage (Fig. 6c, d) and membrane permeability (Fig. 6g, h) were at a similar level in all the plants tested. Only the measurement of the fast-kinetic chlorophyll $a$ fluorescence indicated differences in the efficiency of the photosystem II, which was expressed by the P.I. ${ }_{\mathrm{ABS}}$. parameter (Fig. 6e, f). After treatment at $38{ }^{\circ} \mathrm{C}$ all the mutants gained significantly better/higher values of this parameter than their respected wild types. For example, the mutants that had disturbances in the BR biosynthesis, 522DK and BW084, had $76 \%$ and $63 \%$ higher values of P.I.ABS, respectively, compared to Delisa and Bowman. Temperature of $45{ }^{\circ} \mathrm{C}$ caused markedly higher damage for all the plants tested. Interestingly, all the mutants, except BW084, were characterised by weaker injuries than the wild types. The leaf blade damage for the 522DK mutant was $74 \%$ lower than for the Delisa cultivar. In the case of the BW084 mutant, no differences were observed in the leaf blade damage compared to Bowman. Less damage was observed for BW312 when compared to Bowman and BW084. A much lower membrane permeability_from about $30 \%$ to more than $70 \%$-was observed for all the mutants tested compared to their wild types. Changes in the values of the P.I. ${ }_{\mathrm{ABS}}$ parameter were not observed at $45{ }^{\circ} \mathrm{C}$ for the 522DK and BW084 mutants compared to the wild-type Delisa and Bowman, respectively. However, the P.I. ${ }_{\mathrm{ABS}}$ value was higher in BW312 than in Bowman.

In an earlier experiment, Mazorra et al. (2011) tested the effect of an elevated temperature $\left(45^{\circ} \mathrm{C}\right)$ on the tomato altered BR-sensitive mutant BR ( $\mathrm{curl}^{-a b s}$ ) and an extreme dwarf mutant $\left(d^{x}\right)$. The curl3 mutant is characterised as being BR insensitive (Koka et al. 2000; Bishop 2003). The $d^{x}$ mutant lacks castasterone, but has an elevated level of its precursor 6-deoxocastasterone (Bishop 2003).

In the experiment of Mazorra et al. (2011), approximately $90 \%$ of the curl $^{-a b s}$ seedlings survived high temperatures ( $<30 \%$ of the wild type also survived), which is in line with the results obtained for our BR-signalling mutant BW312.

At the same time, Mazorra et al. (2011) found no differences between the survival rate of the wild-type tomato and the survival of the BR-deficient mutant $d^{x}$. According to the authors, the basic thermotolerance of the tomato mutants was independent of the endogenous level of BR. In our work, regardless of the mutated gene that had caused the BR-deficiency, both the 522DK and BW084 mutants showed even better tolerance to high temperatures than their wild types, but after acclimation at $27^{\circ} \mathrm{C}$. Generally, the results from the publication by Mazorra et al. (2011) and our results give a different picture than obtained in the experiments using exogenous BR treatments (Dhaubhadel et al. 1999, 2002; Mazorra et al. 2011; Zhang et al. 2013, 2014; Wu et al. 2014; Thussagunpanit et al. 2015a, b). In these types of experiments, the artificially increased BR content via their exogenous application stimulated the tolerance to heat. In our work we have presumed that if the BR content decreased in the BR biosynthetic mutants, these plants would have worse thermotolerance-but they did not.

Determining the mechanism of the phenomenon of the better tolerance of the BR mutants to high temperatures will require further studies, but with the present knowledge, in our opinion, part of the explanation of the phenomenon may be simple and seems to be connected to plant height and leaf area. High-temperature treatment is accompanied by increased transpiration, which may additionally cause a water deficit in the leaves along with all the physiological and biochemical consequences that this induces. The mutants tested were semi-dwarf (Gruszka et al. 2011a; Dockter et al. 2014), therefore the areas of the aerial parts of the mutant plants were smaller than in the wild types. This is connected with lower transpiration, which in this case, may have limited the negative physiological consequences of water loss. 
Finally, taking into account the fact that mutants can be part of breeding programs to develop new barley cultivars, information about their tolerance to environmental stresses may be useful.

Acknowledgements The work was funded by a grant from the National Science Centre (2016-2018) No. 2015/17/B/NZ9/01695 (Poland). Support was also provided by the Czech Science Foundation (Grant No. GA17-06613S) for UHPLC-MS/MS analyses of steroids.

Author Contributions IS ad EP made frost and high temperature tests. IS measured PS II efficiency. IS made extraction of all phytohormones. AJ made purification of brassinosteroids on immunoaffinity columns, MD measured phytohormone content (except of brassinosteroids) on UHPLC-MS. JO and ON measured brassinosteroid content on UHPLC-MS/MS. DG provided seeds of mutants for experiment and gave suggestion about interpretation of data. AJ conceived the experimental idea, AJ is coordinator of the project 2015/17/B/NZ9/01695 and she designed experiments and choose all other scientists to cooperation. IS and AJ analyzed and interpreted data. AJ coordinated writing of manuscript. All authors read article and suggested corrections.

\section{Compliance with Ethical Standards}

Conflict of interest The authors have no conflict of interest to declare.

Open Access This article is distributed under the terms of the Creative Commons Attribution 4.0 International License (http://creativeco mmons.org/licenses/by/4.0/), which permits unrestricted use, distribution, and reproduction in any medium, provided you give appropriate credit to the original author(s) and the source, provide a link to the Creative Commons license, and indicate if changes were made.

\section{References}

Bajguz A (2009) Brassinosteroid enhanced the level of abscisic acid in Chlorella vulgaris subjected to short-term heat stress. J Plant Physiol 166:882-886. https://doi.org/10.1016/j.jplph.2008.10.004

Bari R, Jones JDG (2009) Role of plant hormones in plant defence responses. Plant Mol Biol 69:473-488. https://doi.org/10.1007/ s11103-008-9435-0

Bishop GJ (2003) Brassinosteroid mutants of crops. J Plant Growth Regul 22:325-335

Burla B, Pfrunder S, Nagy R, Francisco RM, Lee Y, Martinoia E (2013) Vacuolar transport of abscisic acid glucosyl ester is mediated by ATP-binding cassette and proton-antiport mechanisms in Arabidopsis. Plant Physiol 163:1446-1458. https://doi.org/10.1104/ pp.113.222547

Chono M, Honda I, Zeniya H, Yoneyama K, Saisho D, Takeda K, Takatsuto S, Hoshino T, Watanabe Y (2003) A semidwarf phenotype of barley uzu results from a nucleotide substitution in the gene encoding a putative brassinosteroid receptor. Plant Physiol 133:1209-1219

Delatorre C, Rodríguez A, Rodríguez L, Majada JP, Ordás RJ, Feito I (2017) Hormonal profiling: development of a simple method to extract and quantify phytohormones in complex matrices by UHPLC-MS/MS. J Chromatogr B 1040:239-249. https://doi. org/10.1016/j.chromb.2016.11.007

Dhaubhadel S, Chaudhary S, Dobinson KF, Krishna P (1999) Treatment with 24-epibrassinolide, a brassinosteroid, increases the basic thermotolerance of Brassica napus and tomato seedlings. Plant Mol Biol 40:333-342

Dhaubhadel S, Browning KS, Gallie DR, Krishna P (2002) Brassinosteroid functions to protect the translational machinery and heat-shock protein synthesis following thermal stress. Plant $\mathbf{J}$ 29:681-691. https://doi.org/10.1046/j.1365-313X.2002.01257.x

Divi UK, Rahman T, Krishna P (2010) Brassinosteroid-mediated stress tolerance in Arabidopsis shows interactions with abscisic acid, ethylene and salicylic acid pathways. BMC Plant Biol 10:151. https://doi.org/10.1186/1471-2229-10-151

Dobisova T, Hrdinova V, Cuesta C, Michlickova S, Urbankova I, Hejatkova R, Zadnikova P, Pernisova M, Benkova E, Hejatko J (2017) Light controls cytokinin signaling via transcriptional regulation of constitutively active sensor histidine kinase CKI1. Plant Physiol 174:387-404. https://doi.org/10.1104/pp.16.01964

Dockter C, Gruszka D, Braumann I, Druka A, Druka I, Franckowiak J, Gough S, Janeczko A, Kurowska M, Lundqvist J, Lundqvist U, Marzec M, Matyszczak I, Mullner A, Olkestkova J, Schulz B, Zakhrabekova S, Hansson M (2014) Induced variations in brassinosteroid genes define barley height and sturdiness, and expand the green revolution genetic toolkit. Plant Physiol 166:1912-1927. https://doi.org/10.1104/pp.114.250738

Dziurka M, Janeczko A, Juhász C, Gullner G, Oklestkova J, Novak O, Saja D, Skoczowski A, Tobias I, Barna B (2016) Local and systemic hormonal responses in pepper leaves during compatible and incompatible pepper-tobamovirus interactions. Plant Physiol Biochem 109:355-364. https://doi.org/10.1016/j.plaphy.2016.10.013

Efimova MV, Vankova R, Kusnetsov VV, Litvinovskaya RP, Zlobin IE, Dobrev P, Vedenicheva NP, Savchuk AL, Karnachuk AL, Kudryakova NV, Kuznetsov VV (2017) Effects of 24-epibrassinolide and green light on plastid gene transcription and cytokinin content of barley leaves. Steroids 120:32-40. https://doi. org/10.1016/j.steroids.2016.12.004

El-Yazal SAS, El-Yazal MAS, Dwidar EF, Rady MM (2015) Response of antioxidative defense system in plants grown under some environmental stresses to some antioxidants application view project. Curr Protein Pept Sci 16:000-000. https://doi.org/10.2174/13892 03716666150330141159

Eremina M, Unterholzner SJ, Rathnayake AI, Castellanos M, Khan M, Kugler KG, May ST, Mayer KFX, Rozhon W, Poppenberger B (2016) Brassinosteroids participate in the control of basal and acquired freezing tolerance of plants. Proc Natl Acad Sci 113:5982-5991. https://doi.org/10.1073/pnas.1611477113

Faralli M, Lektemur C, Rosellini D, Gürel F (2015) Effects of heat shock and salnity on barley growth and stress-related gene transcription. Biol Plant 59:537-546. https://doi.org/10.1007/s1053 5-015-0518-x

Fernández H, Doumas P, Bonnet-Masimbert M (1997) Quantification of GA1, GA3, GA4, GA7, GA8, GA9, GA19 and GA20; and GA20 metabolism in dormant and non-dormant beechnuts. Plant Growth Regul 22:29-35

Filek M, Rudolphi-Skórska E, Sieprawska A, Kvasnica M, Janeczko A (2017) Regulation of the membrane structure by brassinosteroids and progesterone in winter wheat seedlings exposed to low temperature. Steroids 128:37-45. https://doi.org/10.1016/j.stero ids.2017.10.002

Grove MD, Spencer GF, Rohwedder WK, Mandava N, Worley JF, Warthen JD, Steffens GL, Flippen-Anderson JL, Cook JC (1979) Brassinolide, a plant growth-promoting steroid isolated from Brassica napus pollen. Nature 281:216-217

Gruszka D, Szarejko I, Maluszynski M (2011a) Identification of barley $D W A R F$ gene involved in brassinosteroid synthesis. Plant Growth Regul 65:343-358. https://doi.org/10.1007/s10725-011-9607-9

Gruszka D, Szarejko I, Maluszynski M (2011b) New allele of HvBRII gene encoding brassinosteroid receptor in barley. J Appl Genet 52:257-268. https://doi.org/10.1007/s13353-011-0031-7 
Gruszka D, Janeczko A, Dziurka M, Pociecha E, Oklestkova J, Szarejko I (2016a) Barley brassinosteroid mutants provide an insight into phytohormonal homeostasis in plant reaction to drought stress. Front Plant Sci 7:1824. https://doi.org/10.3389/fpls.2016.01824

Gruszka D, Gorniak M, Glodowska E, Wierus E, Oklestkova J, Janeczko A, Maluszynski M, Szarejko I (2016b) A reverse-genetics mutational analysis of the barley $H v D W A R F$ gene results in identification of a series of alleles and mutants with short stature of various degree and disturbance in BR biosynthesis allowing a new insight into the process. Int J Mol Sci 17:600. https://doi. org/10.3390/ijms 17040600

Gururani MA, Venkatesh J, Tran L-SP (2015) Regulation of photosynthesis during abiotic stress-induced photoinhibition. Mol Plant 8:1304-1320. https://doi.org/10.1016/j.molp.2015.05.005

Gusta LV, Trischuk R, Weiser CJ (2005) Plant cold acclimation: the role of abscisic acid. J Plant Growth Regul 24:308-318

Hasanuzzaman M, Hossain MA, da Silva JAT, Fujita M (2012) Plant response and tolerance to abiotic oxidative stress: antioxidant defense is a key factor. In: Venkateswarlu B, Shanker A, Shanker C, Maheswari M (eds) Crop stress and its management: perspectives and Strategies. Springer, Dordrecht, pp 261-315

Hedden P (2003) The genes of green revolution. Trends Genet 19:5-8. https://doi.org/10.1016/S0168-9525(02)00009-4

Hedden P, Sponsel V (2015) A century of gibberellin research. J Plant Growth Regul 34:740-760. https://doi.org/10.1007/s0034 4-015-9546-1

Holá D (2011) Brassinosteroids and photosynthesis. In: Hayat S, Ahmad A (eds) Brassinosteroids: a class of plant hormone. Springer Science + Business Media, Berlin, pp 143-192

$\mathrm{Hu}$ Y, Yu D (2014) BRASSINOSTEROID INSENSITIVE2 interacts with ABSCISIC ACID INSENSITIVE5 to mediate the antagonism of brassinosteroids to abscisic acid during seed germination in Arabidopsis. Plant Cell Online 26:4394-4408. https://doi. org/10.1105/tpc.114.130849

Jager CE, Symons GM, Ross JJ, Smith JJ, Reid JB (2005) The brassinosteroid growth response in pea is not mediated by changes in gibberellin content. Planta 221:141-148. https://doi.org/10.1007/ s00425-004-1454-8

Janeczko A, Swaczynova J (2010) Endogenous brassinosteroids in wheat treated with 24-epibrassinolide. Biol Plant 54:477-482. https://doi.org/10.1007/s10535-010-0084-1

Janeczko A, Okleštková J, Pociecha E, Kościelniak J, Mirek M (2011) Physiological effects and transport of 24-epibrassinolide in heatstressed barley. Acta Physiol Plant 33:1249-1259. https://doi. org/10.1007/s11738-010-0655-y

Janeczko A, Gruszka D, Pociecha E, Dziurka M, Filek M, Jurczyk B, Kalaji HM, Kocurek M, Waligórski P (2016) Physiological and biochemical characterisation of watered and drought-stressed barley mutants in the HvDWARF gene encoding C6-oxidase involved in brassinosteroid biosynthesis. Plant Physiol Biochem 99:126141. https://doi.org/10.1016/j.plaphy.2015.12.003

Janeczko A, Biesaga-Kościelniak J, Dziurka M, Filek M, Hura K, Jurczyk B, Kula M, Oklestkova J, Novak O, Rudolphi-Skórska E, Skoczowski A (2018) Biochemical and physicochemical background of mammalian androgen activity in winter wheat exposed to low temperature. J Plant Growth Regul 31:199. https://doi. org/10.1007/s00344-017-9719-1

Janowiak F, Luck E, Dörffling K (2003) Chilling tolerance of maize seedlings in the field during cold periods in spring is related to chilling-induced increase in abscisic acid level. J Agron Crop Sci 189:156-161. https://doi.org/10.1046/j.1439-037X.2003.00027.x

Joo SH, Jang MS, Kim MK, Lee JE, Kim SK (2015) Biosynthetic relationship between $\mathrm{C}_{28}$-brassinosteroids and $\mathrm{C}_{29}$-brassinosteroids in rice (Oryza sativa) seedlings. Phytochemistry 111:84-90. https:// doi.org/10.1016/j.phytochem.2014.11.006
Koka CV, Cerny RE, Gardner RG, Noguchi T, Fujioka S, Takatsuto S, Yoshida S, Clouse SD (2000) A putative role for the tomato genes DUMPY and CURL-3 in brassinosteroid biosynthesis and response. Plant Physiol 122:85-98. https://doi.org/10.1104/ pp.122.1.85

Koyro H-W, Ahmad P, Geissler N (2012) Abiotic stress responses in plants: an overview. In: Ahmad P, Prasad M (eds) Environmental adaptations and stress tolerance of plants in the era of climate change. Springer, New York, pp 1-28

Kudryakova NV, Efimova MV, Danilova MN, Zubkova NK, Khripach VA, Kusnetsov VV, Kulaeva ON (2013) Exogenous brassinosteroids activate cytokinin signalling pathway gene expression in transgenic Arabidopsis thaliana. Plant Growt Regul 70:61-69. https://doi.org/10.1007/s10725-012-9778-z

Kurepin LV, Qaderi MM, Back TG, Reid DM, Pharis RP (2008) A rapid effect of applied brassinolide on abscisic acid concentrations in Brassica napus leaf tissue subjected to short-term heat stress. 55:165-167. https://doi.org/10.1007/s10725-008-9276-5

Larsen A (1978) Freezing tolerance in grasses. Methods for testing in controlled environments. Department of Farm Crops Report no. 195. As, Norway, Sci. Rep. Agr. University Norway

LeClere S, Tellez R, Rampey RA, Matsuda SPT, Bartel B (2002) Characterization of a family of IAA-amino acid conjugate hydrolases from Arabidopsis. J Biol Chem 277:20446-20452. https://doi. org/10.1074/jbc.M111955200

Li B, Zhang C, Cao B, Qin G, Wang W, Tian S (2012) Brassinolide enhances cold stress tolerance of fruit by regulating plasma membrane proteins and lipids. Amino Acids 43:2469-2480. https://doi. org/10.1007/s00726-012-1327-6

Liu Y, Jiang H, Zhao Z, An L (2011) Abscisic acid is involved in brassinosteroids-induced chilling tolerance in the suspension cultured cells from Chorispora bungeana. J Plant Physiol 168:853-862

Mao J, Zhang D, Li K, Liu Z, Liu X, Song C, Li G, Zhao C, Ma J, Han M (2017) Effect of exogenous brassinolide (BR) application on the morphology, hormone status, and gene expression of developing lateral roots in Malus hupehensis. Plant Growth Regul 82:391-401. https://doi.org/10.1007/s10725-017-0264-5

Marzec M, Alqudah AM (2018) Key hormonal components regulate agronomically important traits in barley. Int J Mol Sci 19:795. https://doi.org/10.3390/ijms19030795

Mazorra LM, Holton N, Bishop GJ, Núñez M (2011) Heat shock response in tomato brassinosteroid mutants indicates that thermotolerance is independent of brassinosteroid homeostasis. Plant Physiol Biochem 49:1420-1428. https://doi.org/10.1016/j.plaph y.2011.09.005

Mitchell JW, Mandava N, Worley JF, Plimmer JR, Smith MV (1970) Brassins-a new family of plant hormones from rape pollen. Nature 225:1065-1066. https://doi.org/10.1038/2251065a0

Nakamura A, Higuchi K, Goda H, Fujiwara MT, Sawa S, Koshiba T, Shimada Y, Yoshida S (2003) Brassinolide induces IAA5, IAA19, and DR5, a synthetic auxin response element in Arabidopsis, implying a cross talk point of brassinosteroid and auxin signaling. Plant Physiol 133:1843-1853. https://doi.org/10.1104/ pp.103.030031

Oklestkova J, Tarkowská D, Eyer L, Elbert T, Marek A, Smrzova Z, Novák O, Fránek M, Zhabinskii VN, Strnad M (2017) Immunoaffinity chromatography combined with tandem mass spectrometry: a new tool for the selective capture and analysis of brassinosteroid plant hormones. Talanta 170:432-440. https://doi.org/10.1016/j. talanta.2017.04.044

Oukarroum A, El Madidi S, Strasser RJ (2016) Differential heat sensitivity index in barley cultivars (Hordeum vulgare L.) monitored by chlorophyll $a$ fluorescence OKJIP. Plant Physiol Biochem 105:102-108. https://doi.org/10.1016/j.plaphy.2016.04.015 
Peleg Z, Blumwald E (2011) Hormone balance and abiotic stress tolerance in crop plants. Curr Opin Plant Biol 14:290-295. https://doi. org/10.1016/j.pbi.2011.02.001

Pěnčík A, Simonovik B, Petersson SV, Henykova E, Simon S, Greenham K, Zhang Y, Kowalczyk M, Estelle M, Zažímalová E, Novák O, Sandberg G, Ljung K (2013) Regulation of auxin homeostasis and gradients in Arabidopsis roots through the formation of the indole-3-acetic acid catabolite 2-oxindole-3-acetic acid. Plant Cell 25:3858-3870. https://doi.org/10.1105/tpc.113.114421

Pociecha E, Dziurka M, Oklestkova J, Janeczko A (2016) Brassinosteroids increase winter survival of winter rye (Secale cereale L.) by affecting photosynthetic capacity and carbohydrate metabolism during the cold acclimation process. Plant Growth Regul 80:127-135. https://doi.org/10.1007/s10725-016-0149-z

Pociecha E, Dziurka M, Waligórski P, Krępski T, Janeczko A (2017) 24-Epibrassinolide pre-treatment modifies cold-induced photosynthetic acclimation mechanisms and phytohormone response of perennial ryegrass in cultivar-dependent manner. J Plant Growth Regul 36:618-628. https://doi.org/10.1007/s00344-016-9662-6

Qin G, Gu H, Zhao Y, Ma Z, Shi G, Yang Y, Pichersky E, Chen H, Liu M, Chen Z, Qu LJ (2005) An indole-3-acetic acid carboxyl methyltransferase regulates Arabidopsis leaf development. Plant Cell 17:2693-2704. https://doi.org/10.1105/tpc.105.034959

Reinecke DM, Bandurski RS (1983) Oxindole-3-acetic acid, an Indole3-acetic acid catabolite in Zea mays. Plant Physiol 71:211-213. https://doi.org/10.1104/pp.71.1.211

Roman H, Girault T, Barbier F, Péron T, Brouard N, Pěnčík A, Novák O, Vian A, Sakr S, Lothier J, Le Gourrierec J, Leduc N (2016) Cytokinins are initial targets of light in the control of bud outgrowth. Plant Physiol 172:489-509. https://doi.org/10.1104/pp.16.00530

Sadura I, Janeczko A (2018) Physiological and molecular mechanisms of brassinosteroid-induced tolerance to high and low temperature in plants. Biol Plant 64:601-616. https://doi.org/10.1007/s1053 5-018-0805-4

Shu K, Zhou W, Chen F, Luo X, Yang W (2018) Abscisic acid and gibberellins antagonistically mediate plant development and abiotic stress responses. Front Plant Sci 9:416. https://doi.org/10.3389/ fpls.2018.00416

Skinner JS, von Zitzewitz J, Szucs P, Marquez-Cedillo L, Filichkin T, Amundsen K, Stockinger EJ, Thomashow MF, Chen THH, Hayes PM (2005) Structural, functional, and phylogenetic characterization of a large CBF gene family in barley. Plant Mol Biol 59:533-551. https://doi.org/10.1007/s11103-005-2498-2

Skoczowski A, Janeczko A, Gullner G, Tóbias I, Kornas A, Barna B (2011) Response of brassinosteroid-treated oilseed rape cotyledons to infection with the wild type and HR-mutant of Pseudomonas syringae or with P. fluorescence. J Therm Anal Calorim 104:131-139. https://doi.org/10.1007/s10973-010-1204-z

Small CC, Degenhardt D (2018) Plant growth regulators for enhancing revegetation success in reclamation: a review. Ecol Eng 118:4351. https://doi.org/10.1016/j.ecoleng.2018.04.010

Stanca AM, Crosatti C, Grossi M, Lacerenza NG (1996) Molecular adaptation of barley to cold and drought conditions. Euphytica 92:215-219. https://doi.org/10.1007/BF00022847

Strasser RJ, Srivastava A, Tsimilli-Michael M (2000) The fluorescence transient as a tool to characterize and screen photosynthetic samples. In: Mohanty Y, Mohanty P (eds) Probing photosynthesis: mechanism, aegulation and adaptation. Taylor and Francis, London, pp 445-483

Thussagunpanit J, Jutamanee K, Sonjaroon W, Kaveeta L, Chai-Arree W, Pankean P, Suksamrarn A (2015a) Effects of brassinosteroid and brassinosteroid mimic on photosynthetic efficiency and rice yield under heat stress. Photosynthetica 53:312-320. https://doi. org/10.1007/s11099-015-0106-5

Thussagunpanit J, Jutamanee K, Kaveeta L, Chai-arree W, Pankean P, Homvisasevongsa S, Suksamrarn A (2015b) Comparative effects of brassinosteroid and brassinosteroid mimic on improving photosynthesis, lipid peroxidation, and rice seed set under heat stress. J Plant Growth Regul 34:320-331. https://doi.org/10.1007/s0034 4-014-9467-4

Tian H, Lv B, Ding T, Bai M, Ding Z (2018) Auxin-BR interaction regulates plant growth and development. Front Plant Sci 8:2256. https://doi.org/10.3389/fpls.2017.02256

Tong H, Xiao Y, Liu D, Gao S, Liu L, Yin Y, Jin Y, Qian Q, Chu C (2014) Brassinosteroid regulates cell elongation by modulating gibberellin metabolism in rice. Plant Cell Online 26:4376-4393. https://doi.org/10.1105/tpc.114.132092

Tossi V, Lamattina L, Cassia R (2009) An increase in the concentration of abscisic acid is critical for nitric oxide-mediated plant adaptive responses to UV-B irradiation. New Phytol 181:871-879. https:// doi.org/10.1111/j.1469-8137.2008.02722.x

Unterholzner SJ, Rozhon W, Papacek M, Ciomas J, Lange T, Kugler KG, Mayer KF, Sieberer T, Poppenberger B (2015) Brassinosteroids are master regulators of gibberellin biosynthesis in Arabidopsis. Plant Cell 27:2261-2272. https://doi.org/10.1105/ tpc. 15.00433

Veisz O, Galiba G, Sutka J (1996) Effect of abscisic acid on the cold hardiness of wheat seedlings. J Plant Physiol 149:439-443. https ://doi.org/10.1016/S0176-1617(96)80146-5

Wang H, Tang J, Liu J, Hu J, Liu J, Chen Y, Cai Z, Wang X (2018) Abscisic acid signaling inhibits brassinosteroid signaling through dampening the dephosphorylation of BIN2 by ABI1 and ABI2. Mol Plant 11:315-325. https://doi.org/10.1016/j. molp.2017.12.013

Weiss D, Ori N (2007) Mechanisms of cross talk between gibberellin and other hormones. Plant Physiol 144:1240-1246. https://doi. org/10.1104/pp.107.100370

Welbaum GE, Bian D, Hill DR, Grayson RL, Gunatilaka MK (1997) Freezing tolerance, protein composition, and abscisic acid localization and content of pea epicotyl, shoot, and root tissue in response to temperature and water stress. J Exp Bot 48:643-654. https://doi.org/10.1093/jxb/48.3.643

Wu C, Trieu A, Radhakrishnan P, Kwok SF, Harris S, Zhang K, Wang J, Wan J, Zhai H, Takatsuto S, Matsumoto S, Fujioka S, Feldmann KA, Pennell RI (2008) Brassinosteroids regulate grain filling in rice. Plant Cell 20:2130-2145. https://doi.org/10.1105/ tpc.107.055087

Wu X, Yao X, Chen J, Zhu Z, Zhang H, Zha D (2014) Brassinosteroids protect photosynthesis and antioxidant system of eggplant seedlings from high-temperature stress. Acta Physiol Plant 36:251261. https://doi.org/10.1007/s11738-013-1406-7

Zhang S, Wei Y, Lu Y, Wang X (2009) Mechanisms of brassinosteroids interacting with multiple hormones. Plant Signal Behav 4:1117-1120

Zhang YP, Zhu XH, Ding HD, Yang SJ, Chen YY (2013) Foliar application of 24-epibrassinolide alleviates high-temperature-induced inhibition of photosynthesis in seedlings of two melon cultivars. Photosynthetica 51:341-349. https://doi.org/10.1007/s1109 9-013-0031-4

Zhang YP, He J, Yang SJ, Chen YY (2014) Exogenous 24-epibrassinolide ameliorates high temperature-induced inhibition of growth and photosynthesis in Cucumis melo. Biol Plant 58:311-318. https ://doi.org/10.1007/s10535-014-0395-8

Zhao B, Li J (2012) Regulation of brassinosteroid biosynthesis and inactivation. J Integr Plant Biol 54:746-759. https://doi.org/10.1 111/j.1744-7909.2012.01168.x

Publisher's Note Springer Nature remains neutral with regard to jurisdictional claims in published maps and institutional affiliations. 